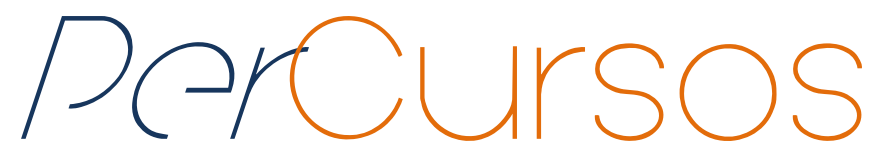

\title{
Mapeamento de risco de escorregamentos da sede urbana do município de Santa Teresa - ES
}

\section{Resumo}

O presente artigo é parte do trabalho executado em dissertação de mestrado acadêmico, que teve como objetivo principal o desenvolvimento de mapeamento de risco de escorregamentos para a Sede Urbana e suas adjacências no município de Santa Teresa - ES, com método distinto do que vem sendo executado após a promulgação da lei 12.608/2012. Como objetivo específico desse estudo, buscou-se também fazer uma comparação entre os outros mapeamentos elaborados para esta área de estudo, a fim de validar o método utilizado e com intenção de apontar novas áreas em que o risco pudesse ser significativo. Nesse mapeamento, utilizou-se um método híbrido de análise para as variáveis que compõem o risco, sendo elas perigo, vulnerabilidade e dano potencial. A comparação foi entre os documentos: setorização de risco alto e muito alto realizado pela Companhia de Pesquisa e Recursos Minerais (CPRM, 2012) e, do Plano Municipal de Redução de Risco Geológico (PMRR), realizado por empresa privada em parceria com o governo do Estado do Espírito Santo, entre o ano de 2012 e 2013. Este método que tem como característica híbrida na sua composição, emprega uma análise paramétrica, de abordagem de paisagem e, também, dos dados referentes ao menor limite administrativo (Setores Censitários) do Censo Demográfico do IBGE (2010), os quais demonstraram que o mapeamento foi conclusivo em observar zonas de expansão da ocupação e qualificar o risco, o perigo, a vulnerabilidade e o dano potencial da área de estudo, elencando áreas proativas para qualificação significativa dessas variáveis.

Palavras-chave: SIG. Lei 12.608/2012. Desastres Ambientais. Avaliação de Riscos Ambientais e Santa Teresa (ES).

\section{Para citar este artigo:}

NASCIMENTO, Thatyane Mônico. Mapeamento de risco de escorregamentos da sede urbana do município de Santa Teresa - ES. Revista PerCursos, Florianópolis, v. 18, n.36, p. 137 - 174, jan./abr. 2017.

\section{DOI: $10.5965 / 1984724618362017137$}

http://dx.doi.org/10.5965/1984724618362017137 


\title{
Mapping of risk to the landslides of the urban headquarters of the municipality of Santa Teresa -
}

\section{ES}

\begin{abstract}
This article is part of the work carried out in an academic master's dissertation, whose main objective was the development of risk mapping for landslides to the urban headquarter sand its environs in the municipality Of Santa Teresa -ES, with a different method executed the enactment of law 12.608/2012. As a specific objective of the study, it was also sought to make a comparison between the other mappings prepared for this area of study, in order to validate the method used and with the intention of pointing out new areas where the rick could be significant. In this mapping, a hybrid method of analysis was used for the variables that compose the risk, which area, danger, vulnerability and potential damage. The comparison it was between the documents: the high and very highrisk settlement, carried out by the Company Research and Mineral Resources (CPRM, 2012) and the Municipal Plan of Geological Risk Reduction (PMRR), carried out by a private company in partnership with the government of the state of Espírito Santo, between 2012 and 2013. This method has as a hybrid feature in its composition employing a parametric analysis, landscape approach and also data regarding the lower administrative limit (Census Sectors) of the IBGE Demographic Census (2010). It demonstrate that the mapping was conclusive in observing areas of occupation expansion and qualifying the risk, vulnerability and potential damage of the studied area, listing proactive areas for significant qualification of these variables.
\end{abstract}

Keywords: GIS. Law 12,608/2012. Environmental Disasters. Environmental Risk assessment. Santa Teresa (ES). 


\section{Introdução}

Análises de risco são antigas na história da sociedade, tanto que o sociólogo Ulrich Beck, denominou a sociedade pós-moderna como a "sociedade do risco", sendo algo inerente a essa sociedade e componente recorrente (ALMEIDA, 2011), sejam eles industriais, tecnológicos ou naturais. Contudo, análises de risco acerca da incidência de desastres naturais e com fins de gestão são recentes e vêm sendo muito orientadas pelas ações tomadas em nível internacional pela Organização das Nações Unidas (ONU), quando decidiu estabelecer a década de 1990 como a Década Internacional para a Redução de Desastres Naturais (DIRDN) - International Decade for Natural Disaster Reduction (IDNDR) (UNISDR, 1989) e continuou este trabalho promovendo marcos de ação e conferências internacionais. No quadro 1 são apresentadas as principais ações fomentadas pela ONU, referentes à história da Gestão de Risco de Desastres em nível global.

Quadro 1- Gestão de risco de desastres em nível global.

\begin{tabular}{|c|c|c|}
\hline \multicolumn{3}{|c|}{ Principais Marcos na História da Gestão de Risco de Desastres } \\
\hline $\begin{array}{l}\text { Final da } \\
\text { Década } \\
\text { de } 1980 \\
\end{array}$ & $\begin{array}{l}\text { Resolução } 44 / 236 \text { - Década } \\
\text { Internacional para a Redução de } \\
\text { Risco (DIRDN) }\end{array}$ & $\begin{array}{l}\text { Estabelecimento do quadro de ação } \\
\text { internacional para a Redução de Desastres } \\
\text { Naturais. }\end{array}$ \\
\hline 1992 & ECO-92 & Estabelecimento da Agenda 21 \\
\hline 1994 & $\begin{array}{l}\text { I Conferência Mundial para a } \\
\text { prevenção de Desastres } \\
\text { Naturais - Yokohama, Japão. }\end{array}$ & $\begin{array}{l}\text { Estratégia e Plano de ação de Yokohama }-1^{\circ} \\
\text { plano para a criação de uma política de } \\
\text { Redução de Desastres. }\end{array}$ \\
\hline 2000 & $\begin{array}{l}\text { Estratégia Internacional para a } \\
\text { Redução de Desastres (ISDR) }\end{array}$ & $\begin{array}{l}\text { Criação do Secretariado permanente sobre a } \\
\text { temática, locado em Genebra, Suíça. }\end{array}$ \\
\hline 2002 & $\begin{array}{l}\text { Plano de Implementação em } \\
\text { Johanesburgo }\end{array}$ & $\begin{array}{l}\text { Plano de priorização das vulnerabilidades à } \\
\text { avaliação de riscos e à gestão de desastres. }\end{array}$ \\
\hline 2005 & $\begin{array}{l}\text { Il Conferência Mundial para a } \\
\text { prevenção de Desastres } \\
\text { Naturais - Kobe, Japão. }\end{array}$ & $\begin{array}{l}\text { Adoção da Declaração de Hyogo por } 168 \\
\text { países membros da ONU e do Quadro de } \\
\text { Ações } 2005 \text {-2015: "Construir a Resiliência } \\
\text { das Nações e das Comunidades face aos } \\
\text { Desastres". }\end{array}$ \\
\hline 2015 & $\begin{array}{l}\text { III Conferência Mundial para a } \\
\text { prevenção de Desastres } \\
\text { Naturais - Sendai, Japão. }\end{array}$ & $\begin{array}{l}\text { Adoção de } 7 \text { novas metas, } 4 \text { prioridades e } 1 \\
\text { conjunto de princípios por } 187 \text { países } \\
\text { membros da ONU sobre o novo Marco de } \\
\text { Hyogo: } 2015-2030 \text {. }\end{array}$ \\
\hline
\end{tabular}

Fonte: NASCIMENTO (2016). Principais marcos e conferências internacionais. 
Observa-se que no último principal marco - a segunda fase de Hyogo (2015-2030), na III Conferência Mundial para a prevenção de Desastres, ocorrida em Sendai no Japão há uma adesão de 187 países membros da ONU, refletindo a importância da atuação das Nações Unidas para que governos nacionais tomem iniciativas mais significativas em reduzir a ocorrência desses eventos, especialmente aqueles que, até então, não haviam se alinhado a diretrizes internacionais. Consequentemente, esse movimento internacional também foi importante para a gestão de risco brasileira, que principiou décadas antes de 1990.

Inicialmente, a preocupação com os desastres no Brasil, surgiu entre 1966 e 1967, devido à ocorrência de eventos pluviométricos intensos na Região Sudeste, principalmente no antigo estado da Guanabara (Rio de Janeiro - RJ), e provocando enchentes e deslizamentos na Serra das Araras e em Caraguatatuba, no estado de São Paulo e, seca na Região Nordeste, o que levou à criação entre esses anos, da primeira Defesa Civil Estadual e do Ministério do Interior, voltado para o atendimento de populações atingidas por calamidades em todo território brasileiro (BRASIL, 2016).

No Ministério do Interior foi criado o Fundo Especial para Calamidades Públicas (FUNCAP) e o Grupo Especial para Assuntos de Calamidades Públicas - GEACAP, vetores essenciais para a criação da SEDEC - Secretaria Nacional de Defesa Civil, que por meio do Decreto $\mathrm{n}^{\circ}$ 97.274, de 16 de dezembro de 1988, passou a figurar como responsável pela prevenção de desastres e também organizou o SINDEC - Sistema Nacional de Defesa Civil (BRASIL, 2016).

Ainda em 1988, data deste Decreto, temos uma iniciativa ímpar na história de Redução de Risco de Desastres (RRD) específica para escorregamentos nas encostas da Serra do Mar no estado de São Paulo, após acidentes em larga escala com ocorrência de vítimas fatais, criando-se assim o Plano Preventivo de Defesa Civil - PPDC (SÃO PAULO, 2004) que, posteriormente, foi redefinido pelo Decreto $n^{\circ} 42.565$, de $1^{\circ}$ de dezembro de 1997. Ainda utilizado pelas defesas civis, instrumento de referência, vigora anualmente entre os meses de dezembro e março, com a participação do Instituto Geológico, da Defesa Civil Estadual e do IPT/SP (Instituto de Pesquisas Tecnológicas de São Paulo), órgãos esses que são referência em âmbito nacional no que diz respeito à prevenção, 
mitigação, preparação, resposta e reconstrução a desastres naturais. Na figura 1 são

apresentados os níveis operacionais do PPDC.

\begin{tabular}{|c|c|c|c|}
\hline $\begin{array}{l}\text { Nível } \\
\text { do } \\
\text { Plano }\end{array}$ & $\begin{array}{c}\text { Critério de } \\
\text { Entrada no } \\
\text { Nivel }\end{array}$ & Açōes a Serem Executadas pelo Município & $\begin{array}{l}\text { Açōes a Serem } \\
\text { Executadas pelo } \\
\text { Apoio Técnico }\end{array}$ \\
\hline 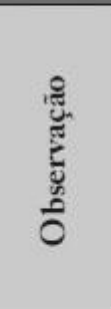 & $\begin{array}{l}\text { Início da } \\
\text { operação do } \\
\text { plano. }\end{array}$ & $\begin{array}{l}\text {-Conscientização da população das áreas de risco; } \\
\text {-Obtenção do dado pluviométrico; } \\
\text {-Cálculo do acumulado de chuvas; } \\
\text {-Recebimento da previsão meteorológica; } \\
\text {-Transmissão para o apoio técnico do dado } \\
\text { pluviométrico e nível vigente; } \\
\text {-Avaliação da necessidade de MUDANÇA DE } \\
\text { NÍVEL. }\end{array}$ & $\begin{array}{l}\text {-Manter técnicos } \\
\text { em plantão para } \\
\text { acompanhamento } \\
\text { e análise da } \\
\text { situação; } \\
\text {-Enviar previsões } \\
\text { meteorológicas. }\end{array}$ \\
\hline 氖 & $\begin{array}{l}\text { Quando o } \\
\text { acumulado } \\
\text { de chuvas } \\
\text { ultrapassar } \\
\text { o valor de } \\
\text { referência } \\
\text { combinado } \\
\text { com a previsão } \\
\text { meteorológica. }\end{array}$ & $\begin{array}{l}\text {-Declarar MUDANÇA DE NÍVEL; } \\
\text {-Comunicar ao apoio técnico sobre MUDANÇA } \\
\text { DE NÍVEL; } \\
\text {-Realizar VISTORIAS de campo visando } \\
\text { verificar a ocorrência de deslizamentos e feiçóes de } \\
\text { instabilização. Devem ser iniciadas pelas áreas de } \\
\text { risco; } \\
\text {-Obtenção do dado pluviométrico; } \\
\text {-Cálculo do acumulado de chuvas; } \\
\text {-Recebimento da previsão meteorológica; } \\
\text {-Transmissão ao apoio técnico do dado } \\
\text { pluviométrico e nível vigente; } \\
\text {-Avaliação da necessidade de MUDANÇA DE } \\
\text { NÍVEL. }\end{array}$ & $\begin{array}{l}\text {-Manter técnicos } \\
\text { em plantão para } \\
\text { acompanhamento } \\
\text { e análise da } \\
\text { situação; } \\
\text {-Enviar previsões } \\
\text { meteorológicas. }\end{array}$ \\
\hline$\stackrel{\frac{\pi}{2}}{\grave{2}}$ & $\begin{array}{l}\text { Quando as } \\
\text { vistorias de } \\
\text { campo indicarem } \\
\text { a existência } \\
\text { de feiçốes de } \\
\text { instabilidade } \\
\text { ou mesmo } \\
\text { deslizamentos } \\
\text { pontuais. }\end{array}$ & $\begin{array}{l}\text {-Declarar MUDANÇA DE NÍVEL; } \\
\text {-Comunicar ao apoio técnico sobre MUDANÇA } \\
\text { DE NÍVEL; } \\
\text {-Realizar VISTORIAS de campo; } \\
\text {-Retirada da população das áreas de risco iminente; } \\
\text {-Obtenção do dado pluviométrico; } \\
\text {-Cálculo do acumulado de chuvas; } \\
\text {-Recebimento da previsão meteorológica; } \\
\text {-Transmissão ao apoio técnico do dado } \\
\text { pluviométrico e nível vigente; } \\
\text {-Agilizar os meios necessários para POSSÍVEL } \\
\text { retirada da população das demais áreas de risco; } \\
\text {-Avaliação da necessidade de MUDANÇA DE } \\
\text { NÍVEL. }\end{array}$ & $\begin{array}{l}\text {-Deslocamento } \\
\text { de técnicos para } \\
\text { acompanhamento } \\
\text { da situação e } \\
\text { avaliação da } \\
\text { necessidade } \\
\text { de medidas } \\
\text { complementares; } \\
\text {-Enviar previsões } \\
\text { meteorológicas. }\end{array}$ \\
\hline 这 & $\begin{array}{l}\text { Quando } \\
\text { ocorrerem } \\
\text { deslizamentos } \\
\text { generalizados. }\end{array}$ & $\begin{array}{l}\text {-Declarar MUDANÇA DE NÍVEL; } \\
\text {-Comunicar ao apoio técnico sobre MUDANÇA } \\
\text { DE NÍVEL; } \\
\text {-Proceder a retirada da população das áreas de risco } \\
\text { e demais áreas necessárias; } \\
\text { - Obtenção do dado pluviométrico; } \\
\text {-Cálculo do acumulado de chuvas; } \\
\text {-Recebimento da previsão meteorológica; } \\
\text {-Transmissão ao apoio técnico do dado } \\
\text { pluviométrico e nível vigente; } \\
\text {-Avaliação da necessidade de MUDANÇA DE } \\
\text { NÍVEL. }\end{array}$ & $\begin{array}{l}\text {-Deslocamento } \\
\text { de técnicos para } \\
\text { acompanhamento } \\
\text { da situação e } \\
\text { avaliação da } \\
\text { necessidade } \\
\text { de medidas } \\
\text { complementares; } \\
\text {-Enviar previsões } \\
\text { meteorológicas. }\end{array}$ \\
\hline
\end{tabular}

Figura 1 - Níveis Operacionais do Plano Preventivo de Defesa Civil. Fonte: MACEDO; OGURA; SANTORO (2006). Níveis operacionais de PPDC. 
Em 1995, em alinhamento com a DIRDN, é instaurada no Brasil a Política Nacional de Defesa Civil (PNDC), que criou um plano nacional de redução de desastres com programas e metas para serem alcançadas até o ano 2000, estruturadas em quatro pilares: minimização (prevenção e preparação), resposta e reconstrução frente aos desastres. Este plano continha quatro diretrizes que previam (I) reestruturação da SEDEC como Secretaria Especial de Defesa Civil; (II) classificação dos desastres que compunham a realidade brasileira; (III) organização de manuais de planejamento em Defesa Civil; e (IV) criação de um programa de capacitação em desastres (BRASIL, 2016).

Assim, o Brasil deu os seus primeiros passos para a Gestão de Risco de Desastres em âmbito nacional, organizando seu corpo técnico e fornecendo capacitação sobre a temática. Entretanto, no findar dessa década e nos anos subsequentes, observou-se que as medidas adotadas pelo governo brasileiro não estavam sendo suficientes, especialmente após os eventos de alto índice pluviométrico que assolaram a Região Serrana do Rio de Janeiro em 2011, atingindo milhares de pessoas e ocasionando diversos danos e prejuízos de ordem econômica, social e ambiental. Estes eventos demonstraram que as políticas precisavam ser revistas, em busca de uma cultura de prevenção e não de resposta a essas catástrofes; com isso, foi instaurada a Política Nacional de Proteção e Defesa Civil (PNPDEC) estabelecida pela lei federal 12.608/2012, em substituição à PNDC de 1995 .

A lei 12.608/2012 autoriza a criação do sistema de informações e monitoramento de desastres, fazendo jus assim, à inserção do termo Prevenção no título da política. Ela abrange as ações de prevenção, mitigação, preparação, resposta e recuperação voltadas à proteção e defesa civil, em que a mesma deve integrar-se às políticas de ordenamento territorial, desenvolvimento urbano, saúde, meio ambiente, mudanças climáticas, gestão de recursos hídricos, geologia, infraestrutura, educação, ciência e tecnologia e às demais políticas setoriais, a fim de promover o desenvolvimento sustentável (BRASIL, 2012).

Entre uma série de diretrizes e objetivos da PNPDEC, compete à União no art. $6^{\circ}$, inciso IV, V, VI, apoiar os estados, Distrito Federal e os municípios no mapeamento das áreas de risco, bem como manter um sistema de informações e monitoramento de desastres além de um cadastro de áreas suscetíveis a processos de grande impacto 
geológico e hidrológico. A lei ainda dispõe no mesmo artigo, no inciso XII, fomentar a pesquisa sobre os eventos deflagradores de desastres.

Dentro dessas diretrizes são elencadas na figura 2, as ações por Ministérios referentes à nova política, com foco nas medidas adotadas pelos Ministérios de Minas e Energia; Meio Ambiente; Ciência, Tecnologia e Informação; e Cidades, que operam com foco em prevenção dos desastres, juntamente com o Ministério da Integração, que também atua em outros âmbitos.

\begin{tabular}{|c|c|}
\hline MINISTÉRIO & AÇÃO \\
\hline \multirow{3}{*}{ Ministério do Planejamento, Orçamento e Gestão (MPOG) } & Obras de contenção de encostas (PAC) \\
\hline & Obras de drenagem (PAC) \\
\hline & Obras de barragem (PAC) \\
\hline \multirow{7}{*}{ Ministério da Integração Nacional (MI) } & Mapeamento de Riscos e Desastres \\
\hline & Recursos para resposta a desastres \\
\hline & Cartão de Pagamento de Defesa Civil \\
\hline & Kits de Assistência Humanitária \\
\hline & Força Nacional de Emergência \\
\hline & Fortalecimento das Defesas Civis \\
\hline & Capacitação de Agentes \\
\hline \multirow{2}{*}{ Ministério de Minas e Energia (MME) } & Mapeamento de Risco Geológico \\
\hline & Mapeamento de Suscetibilidade a Movimentos de Massa e Inundações \\
\hline \multirow{2}{*}{ Ministério do Meio Ambiente (MMA) } & Mapeamento de Risco Hidrológico \\
\hline & Salas de Situação \\
\hline \multirow{4}{*}{ Ministério da Ciência, Tecnologia e Informação (MCTI) } & Radares \\
\hline & Pluviômetros \\
\hline & Estações Hidrológicas \\
\hline & Equipamentos Geotécnicos \\
\hline Ministério das Cidades (MCIDADES) & Cartas Geotécnicas de Aptidão à Urbanização \\
\hline \multirow{2}{*}{ Ministério da Saúde (MS) } & Força Nacional do SUS \\
\hline & Kits de Medicamentos \\
\hline Estado-Maior Conjunto das Forças Armadas (EMCFA) & Fortalecimento das Forças Armadas \\
\hline
\end{tabular}

Figura 2 - Ações por Ministério após a instauração da PNPDEC. Elaborado por CEPED UFSC (2015). Fonte: DALMAU; MACHAD; FRAN (2015).

Atividades para RRD por Ministério. Fonte: DALMAU; MACHAD; FRAN (2015). 
Neste contexto, é importante ressaltar a criação do CEMADEM - Centro Nacional de Monitoramento e Alertas de Desastres Naturais, em julho de 2011, com o objetivo principal de contribuir com o decréscimo do fatalismo acarretado pelos desastres naturais e da vulnerabilidade social, ambiental e econômica decorrente deles (BRASIL, 2017), e da criação da "Sala de Situação" do Setor de Operação e Modelagem, que monitora 888 municípios com histórico de desastres naturais 24 horas por dia (ASCOM, 2015), criada em 2014. A Sala de Situação interliga suas informações com o CENAD Centro Nacional de Gerenciamento de Desastres, que atua em duas frentes de trabalho apresentadas no quadro 2.

Quadro 2-CENAD.

\begin{tabular}{|c|c|}
\hline \multicolumn{2}{|r|}{ Centro Nacional de Gerenciamento de Riscos e Desastres } \\
\hline Objetivo & $\begin{array}{l}\text { Gerenciar, com agilidade, ações estratégicas de preparação e } \\
\text { resposta a desastres em território nacional e, eventualmente, } \\
\text { também no âmbito internacional. }\end{array}$ \\
\hline $\begin{array}{l}\text { Frente de } \\
\text { atuação }\end{array}$ & $\begin{array}{l}\text { - Preparação e resposta a desastres: mobilização para atendimento } \\
\text { às vítimas; } \\
\text { - Monitoramento, alerta, informação, mobilização E resposta: } \\
\text { monitoramento constante de informações sobre possíveis desastres } \\
\text { em áreas de risco, com o objetivo de reduzir impactos e preparar a } \\
\text { população. }\end{array}$ \\
\hline Ações & $\begin{array}{l}\text { Consolidar as informações sobre riscos no País: mapas de áreas de } \\
\text { risco, dados relativos à ocorrência de desastres naturais e } \\
\text { tecnológicos e os danos associados. }\end{array}$ \\
\hline Funcionamento & $\begin{array}{l}\text { Recebimento de informações de diversos órgãos do governo federal } \\
\text { responsáveis pela predição de tempo e temperatura; avaliação de } \\
\text { condições geológicas de áreas de risco; monitoramento dos } \\
\text { movimentos das placas tectônicas; acompanhamento das bacias } \\
\text { hidrográficas; controle de queimadas e incêndios florestais; e } \\
\text { transporte e armazenamento de produtos perigosos; }\end{array}$ \\
\hline Responsabilidade & $\begin{array}{l}\text { - Planejamento e mobilizações para atuação em situação de riscos e } \\
\text { de desastres; } \\
\text { - Coordena o Grupo de Apoio a Desastres (GADE). }\end{array}$ \\
\hline
\end{tabular}

Fonte: NASCIMENTO (2016). Caraterísticas de atuação de CENAD. 
Tendo em vista suas frentes de atuação e ações, o CENAD consolida informações como os mapeamentos de risco que vêm sendo elaborados no Brasil. Os primeiros trabalhos surgiram no final da década de 1980, como os de Prandini et al. (1987) e Sobreira (1989); a partir deles, evidenciou-se que são produtos fundamentais para o gerenciamento e RRD e suas possíveis consequências para a sociedade, pois assim, é possível conhecer a dinâmica do relevo e evitar que esses processos causem acidentes (TOMINAGA, 2009).

Atualmente, à responsabilidade do governo federal, órgãos como o Instituto de Pesquisa Tecnológica de São Paulo (IPT-SP), a Companhia de Pesquisa e Recursos Minerais (CPRM), do Serviço Geológico do Brasil (SGB) e o Instituto Geológico de São Paulo (IG-SP), que há décadas desenvolve esse tipo de estudo para o Estado de São Paulo e atua também em episódios ocorridos ao longo do território nacional, estão a cargo de desenvolver ferramentas e mapeamentos que auxiliem na gestão do risco e mitigação de desastres naturais, assim como os municípios, que em parceria com empresas privadas e com o governo estadual têm elaborado Planos Municipais de Redução de Risco (PMRR).

Tais mapeamentos que passaram a ser desenvolvidos em quase todo o território nacional após o advento da lei 12.608/2012, têm servido às Defesas Civis Municipais como instrumentos de gestão de risco dessas áreas e operam em consonância como o que está descrito na lei. No quadro 3 são apresentados os principais tipos de mapeamentos desenvolvidos pelos órgãos supracitados. 
Quadro 3 - Instituições Pesquisa e principais mapeamentos desenvolvidos.

\begin{tabular}{|c|c|c|c|c|c|}
\hline $\begin{array}{l}\text { Insti- } \\
\text { tuição }\end{array}$ & Histórico & Objetivo & Atuação & Mapeamento (s) & $\begin{array}{l}\text { Objetivos do (s) } \\
\text { mapeamento (s) }\end{array}$ \\
\hline CPRM & $\begin{array}{l}\text { Realiza } \\
\text { mapeamentos } \\
\text { desde } 1990 \text { com um } \\
\text { programa voltado à } \\
\text { disponibilização de } \\
\text { informações básicas: } \\
\text { mapas temáticos de } \\
\text { geologia, } \\
\text { hidrogeologia, } \\
\text { morfologia, etc. }\end{array}$ & $\begin{array}{l}\text { Realizar mapas } \\
\text { Geoambientais para } \\
\text { suporte ao } \\
\text { ordenamento } \\
\text { territorial: } \\
\text { planejamento do uso } \\
\text { e ocupação } \\
\text { adequados ao solo; } \\
\text { planos diretores de } \\
\text { bacias hidrográficas e } \\
\text { de desenvolvimento } \\
\text { de regiões } \\
\text { metropolitanas. }\end{array}$ & $\begin{array}{l}\text { Atua em consonância } \\
\text { com o Plano Nacional } \\
\text { de Gestão de Risco e } \\
\text { Resposta a Desastres } \\
\text { Naturais (PNGRRDN) } \\
\text { em: 1) mapeamento; } \\
\text { 2) prevenção; 3) } \\
\text { monitoramento e } \\
\text { alerta; 4) resposta. }\end{array}$ & $\begin{array}{l}\text { - Setorização dos } \\
\text { riscos a } \\
\text { escorregamentos } \\
\text { e inundações } \\
\text { (alto e muito } \\
\text { alto); } \\
\text { - Cartas de } \\
\text { Suscetibilidade a } \\
\text { movimentos de } \\
\text { massa e } \\
\text { inundações } \\
\text { (juntamente com } \\
\text { o IPT/SP). }\end{array}$ & $\begin{array}{l}\text { Disponibilizar ao } \\
\text { CEMADEM as } \\
\text { áreas } \\
\text { identificadas } \\
\text { como risco alto e } \\
\text { muito alto para } \\
\text { emissão de } \\
\text { alertas para } \\
\text { prevenção das } \\
\text { comunidades. } \\
\text { Integra } \\
\text { informações } \\
\text { com o CENAD e a } \\
\text { SEDEC. }\end{array}$ \\
\hline IPT/SP & $\begin{array}{l}\text { Realiza trabalhos de } \\
\text { cartografia } \\
\text { geotécnica desde a } \\
\text { década de } 1970 \text { para } \\
\text { prefeituras e } \\
\text { governos estaduais, } \\
\text { com destaque para a } \\
\text { Carta desenvolvida } \\
\text { para os Morros de } \\
\text { Santos e São } \\
\text { Vicente, em 1979. }\end{array}$ & $\begin{array}{l}\text { Produzir cartas que } \\
\text { identificam problemas } \\
\text { potenciais em área de } \\
\text { interesse, entendidos } \\
\text { como a } \\
\text { suscetibilidade do } \\
\text { terreno; auxilia } \\
\text { metodologicamente } \\
\text { estudos do governo } \\
\text { federal para o PDAP e } \\
\text { o PMRR. }\end{array}$ & $\begin{array}{l}\text { A metodologia de } \\
\text { atuação está disposta } \\
\text { em } 4 \text { etapas } \\
\text { principais: (a) } \\
\text { formulação de uma } \\
\text { hipótese ou modelo } \\
\text { inicial orientativo; (b) } \\
\text { análise } \\
\text { fenomenológica e de } \\
\text { desempenho; (c) } \\
\text { mapeamento e } \\
\text { compartimentação; e } \\
\text { (d) representação. }\end{array}$ & $\begin{array}{l}\text { - Carta Geotécnica } \\
\text { de } \\
\text { Suscetibilidade; } \\
\text { - Carta Geotécnica } \\
\text { de aptidão } \\
\text { urbanística frente } \\
\text { aos desastres } \\
\text { naturais para o } \\
\text { parcelamento do } \\
\text { solo. }\end{array}$ & $\begin{array}{l}\text { Subsidiar } \\
\text { gestores no } \\
\text { planejamento } \\
\text { urbano e indicar } \\
\text { áreas que } \\
\text { necessitam de } \\
\text { estudos com } \\
\text { uma escala } \\
\text { maior de } \\
\text { detalhes. }\end{array}$ \\
\hline IG-SP & $\begin{array}{l}\text { Realiza trabalhos } \\
\text { sobre desastres } \\
\text { naturais há mais de } \\
20 \text { anos. Instituição } \\
\text { ligada a Secretaria } \\
\text { de Meio Ambiente } \\
\text { do Estado de São } \\
\text { Paulo (SMA-SP), } \\
\text { produzindo o seu } \\
\text { primeiro estudo } \\
\text { integrado em 1987, } \\
\text { com o } \\
\text { mapeamento das } \\
\text { regiões de } \\
\text { Sorocaba e } \\
\text { Campinas. }\end{array}$ & $\begin{array}{l}\text { Prevenção e mitigação } \\
\text { de desastres naturais; } \\
\text { desenvolver ações e } \\
\text { instrumentos de } \\
\text { gestão ambiental e de } \\
\text { ordenamento } \\
\text { territorial no âmbito } \\
\text { da SMA-SP. }\end{array}$ & $\begin{array}{l}\text { Atua na elaboração } \\
\text { de planos diretores } \\
\text { municipais, } \\
\text { zoneamentos } \\
\text { ambientais, } \\
\text { Zoneamento } \\
\text { Ecológico- } \\
\text { Econômico (ZEE), } \\
\text { Plano Estadual de } \\
\text { Gerenciamento } \\
\text { Costeiro, Planos de } \\
\text { Manejo de Unidades } \\
\text { de Conservação, } \\
\text { gerenciamento de } \\
\text { riscos geoambientais } \\
\text { e em ações de } \\
\text { prevenção dos riscos } \\
\text { da Defesa Civil, de } \\
\text { licenciamento } \\
\text { ambiental e de } \\
\text { fiscalização. }\end{array}$ & $\begin{array}{l}\text { Mapeamento } \\
\text { desenvolvido por } \\
\text { método de } \\
\text { abordagem de } \\
\text { paisagem com a } \\
\text { criação de } \\
\text { Unidades } \\
\text { Territoriais } \\
\text { Básicas (UTBs) } \\
\text { elencando setores } \\
\text { de risco. }\end{array}$ & $\begin{array}{l}\text { Desenvolver } \\
\text { cartografia } \\
\text { geotécnica } \\
\text { voltada a } \\
\text { avaliação de } \\
\text { risco geológico } \\
\text { por } \\
\text { compartimentaç } \\
\text { ão fisiográfica e } \\
\text { do uso e } \\
\text { cobertura da } \\
\text { terra. }\end{array}$ \\
\hline
\end{tabular}

Elaborado pelo autor. Principais metodologias de mapeamentos desenvolvidos no Brasil após a lei 12.608/2012. Baseado em SILVA (2004); TOMINAGA (2007); DINIZ et al. (2012). 
Este trabalho buscou realizar novo mapeamento com metodologia híbrida, baseado nos métodos das instituições reconhecidas - CPRM, IPT/SP e IG/SP - focalizando principalmente na metodologia desenvolvida pelo Instituto Geológico de São Paulo, com o método de abordagem de paisagem. Buscou-se também, fazer uma comparação entre os documentos de mapeamento da CPRM - Setorização de risco alto e muito alto - e do PMRR, utilizando ferramentas de Sistemas de Informações Geográficas (SIG) e integrando outros dados que já estivessem disponíveis para a sociedade civil, como o Setores Censitários do Instituto Brasileiro de Geografia e Estatística (IBGE), do Censo Demográfico de 2010.

A área de estudo escolhida foi a Sede Urbana do Município de Santa Teresa, no Espírito Santo, Região Serrana do Estado, (Figura 3). Trata-se de uma área urbana com boa parte de mata nativa ainda preservada, localizada em meio a cultivos agrícolas e ocupação não totalmente consolidada em algumas porções, sendo interessante nesse contexto, pois é uma Sede Urbana que está em plena expansão de sua ocupação, e por isso, se faz ainda mais necessária a produção de estudos que possam subsidiar o ordenamento territorial e o planejamento do uso adequado à cobertura da terra. 

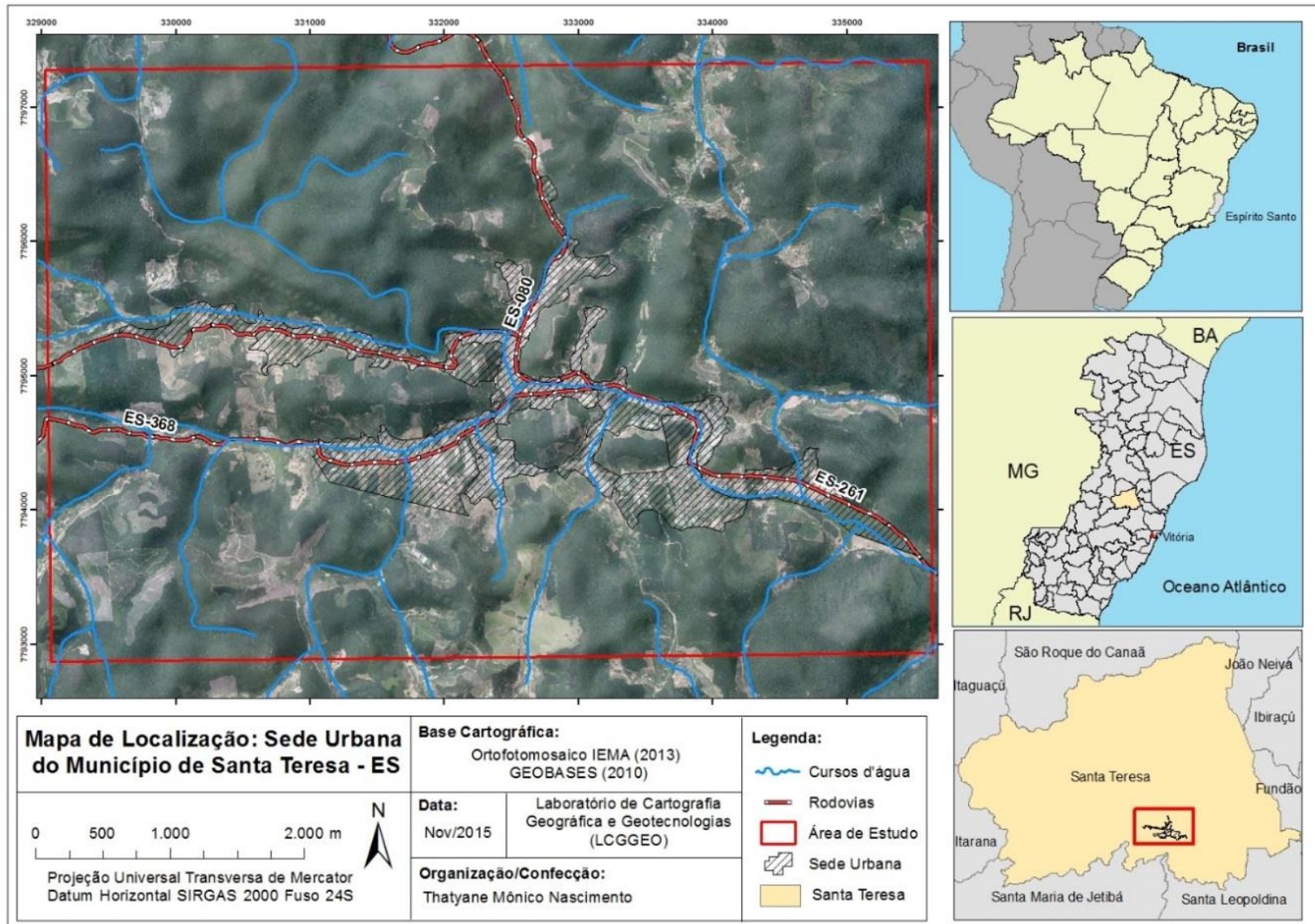

Figura 3 - Mapa de localização da área de estudo. Elaborado pelo autor.

Localização área de estudo assinalada em vermelho, que compreende a Sede Urbana de Santa Teresa - ES.

Os condicionantes do meio físico também são ressaltados, quando observa-se que o limite da sede é um vale estreito cercado por vertentes, em boa parte, com declividades superiores a $30 \%$ de inclinação. A conjunção desses dois fatores cria uma zona de dispersão dessa população, que tentando escapar de processos como o de inundação se dispõe sobre as partes médias e altas dessas vertentes e acaba ficando exposta a outro tipo de fenômeno, os escorregamentos.

Outro motivo para a escolha desta área é que como buscou-se fazer uma comparação entre os mapeamentos da CPRM e do PMRR, estes deveriam estar disponíveis para consulta em meio físico e/ou digital, fornecidos de seus relatórios técnicos e bases cartográficas. Do início da execução desta pesquisa, em 2014, dos municípios mapeados até esta data', Santa Teresa - ES apresentou em seus relatórios

\footnotetext{
${ }^{1}$ Atualmente, o Espírito Santo tem todo os seus 78 municípios mapeados (CPRM, 2016).
} 
técnicos alterações antrópicas significativas em suas vertentes, chamando a atenção para ser eleita como área de estudo.

\section{Metodologia}

Os mapeamentos de risco, de acordo com Ferreira (2011), têm sido elaborados a partir de duas abordagens de análise espacial: 1) abordagem paramétrica e 2) abordagem de paisagem, aportadas na cartografia Geotécnica. A primeira, consiste na sobreposição de mapas temáticos, tais como: geológico, geomorfológico, pedológico, vegetação, entre outros, em que normalmente, as unidades de análise possuem pixel com características geográficas próprias. Na segunda, as Unidades são escolhidas, a priori, por meio da interpretação de imagens de satélite, em que são definidas Unidades Territoriais básicas (UTBs) que correspondem à menor parte de análise da paisagem; essas informações são divididas em dois planos: as Unidades Básicas de Compartimentação do Meio Físico (UBCs), compreendendo o substrato geológico; e as Unidades Homogêneas do Uso e Cobertura da Terra (UHCTs) relacionadas às características socioeconômicas.

Optou-se por trabalhar com uma metodologia híbrida, fazendo uso da análise paramétrica e de partes dos preceitos utilizados pelo método de abordagem de paisagem, porém sem a escolha, a priori, de UTBs, tendo como respaldo para os fatores e pesos empregados na modelagem do mapa final, os mesmos que foram utilizados na metodologia de Abordagem de Paisagem desenvolvida por Ferreira e Rossini-Penteado (2011). Também foram utilizados dados do Censo Demográfico realizado pelo IBGE para o ano de 2010, fazendo com que o mapa de Risco final fosse setorizado, de acordo com essas menores unidades administrativas, ou seja, os Setores Censitários.

Cada tipo de método foi empregado em uma análise das variáveis que compõem a fórmula de Risco utilizada, na qual considera-se a terminologia de Tominaga (2007), sendo o Risco:

Possibilidade de se ter consequências prejudiciais ou danosas em função de perigos naturais ou induzidos pelo homem. Assim, considera-se o Risco (R) como uma função do Perigo (P), da Vulnerabilidade (V) e do 
Dano Potencial (DP), o qual pode ser expresso como: $\mathrm{R}=\mathrm{P} \times \mathrm{V} \times \mathrm{DP}$. (TOMINGA, 2007, p. 49)

Assim, para cada variável da fórmula, há um conjunto de fatores a serem processados em ambiente de SIG, tendo sido utilizado o Software Arcgis 10.3. Desta forma, foram atribuídos pesos entre 0 - 1 para as variáveis e para as classes dos fatores, em que o representa a influência mínima e 1 a influência máxima. Os fatores e os métodos utilizados podem ser observados no quadro 4. Por fim, procedeu-se uma etapa de campo para checagem e validação do mapeamento produzido em gabinete.

\section{Procedimentos operacionais}

Todos os padrões utilizados para atribuição de pesos e fatores analisados seguem parte da metodologia empregada por Ferreira \& Rossini-Penteado (2011). Os valores de célula de pixel das informações processadas em SIG tiveram tamanho 10 e os planos de informação utilizados estão descritos no quadro 5 .

Quadro 4 - Aspectos metodológicos dos fatores que compõem o Risco.

\begin{tabular}{|c|c|c|c|c|c|c|}
\hline $\mathbf{R}$ & Variáveis & Fatores & Sigla & $\begin{array}{l}\text { Aspectos } \\
\text { metodológicos }\end{array}$ & Observações & Método \\
\hline \multirow{6}{*}{$\mathrm{P}$} & \multirow{6}{*}{ Perigo } & 1.Amplitude & M & \multirow{5}{*}{$\begin{array}{l}\text { Processamento } \\
\text { de informações } \\
\text { em ambiente } \\
\text { SIG e } \\
\text { sobreposição } \\
\text { em abordagem } \\
\text { paramétrica } \\
\text { com atribuição } \\
\text { de pesos, de } \\
\text { acordo, com } \\
\text { metodologia de } \\
\text { Ferreira e } \\
\text { Rossini } \\
\text { Penteado } \\
\text { (2011). }\end{array}$} & \multirow{5}{*}{$\begin{array}{l}\text { Divisão em } 5 \\
\text { classes para } \\
\text { cada fator, de } \\
\text { acordo com a } \\
\text { influência, } \\
\text { sendo: Muito } \\
\text { Baixa, Baixa } \\
\text { Média, Alta e } \\
\text { Muito Alta. }\end{array}$} & \multirow{6}{*}{$\begin{array}{l}\text { Abordagem } \\
\text { Paramétrica }\end{array}$} \\
\hline & & 2.Declividade Média & $\mathrm{E}$ & & & \\
\hline & & 3.Densidade de Drenagem & D & & & \\
\hline & & $\begin{array}{l}\text { 4.Densidade de } \\
\text { Lineamentos }\end{array}$ & L & & & \\
\hline & & 5.Excedente Hídrico & $\mathrm{H}$ & & & \\
\hline & & 6.Uso e cobertura da terra & 1 & $\begin{array}{l}\text { Enquadrament } \\
\text { o das classes, } \\
\text { de acordo, com } \\
\text { metodologia de } \\
\text { Ferreira \& }\end{array}$ & $\begin{array}{l}\text { Os pesos são } \\
\text { apresentados na } \\
\text { tabela } 1 .\end{array}$ & \\
\hline
\end{tabular}




\begin{tabular}{|c|c|c|c|c|c|c|}
\hline & & & & $\begin{array}{l}\text { Rossini- } \\
\text { Penteado } \\
\text { descrita em São } \\
\text { Paulo (2014). } \\
\text { Todas as classes } \\
\text { na variável de } \\
\text { Perigo } \\
\text { obtiveram } \\
\text { atribuição de } \\
\text { pesos conforme } \\
\text { possibilidade de } \\
\text { perigo à } \\
\text { ocupação. }\end{array}$ & & \\
\hline \multirow{8}{*}{ V } & \multirow{8}{*}{ Vulnerabilidade } & $\begin{array}{l}\text { 1.Índice de Abastecimento } \\
\text { de Água }\end{array}$ & A & \multirow{8}{*}{$\begin{array}{l}\text { Fatores } \\
\text { estabelecidos, } \\
\text { de acordo, com } \\
\text { metodologia de } \\
\text { Ferreira e } \\
\text { Rossini- } \\
\text { Penteado } \\
\text { (2011), em que } \\
\text { foram } \\
\text { enquadrados } \\
\text { em classes com } \\
\text { pesos } \\
\text { definidos, } \\
\text { também } \\
\text { conforme essa } \\
\text { metodologia } \\
\text { para os Setores } \\
\text { censitários do } \\
\text { IBGE com } \\
\text { dados do Censo } \\
\text { Demográfico de } \\
\text { 2010, para a } \\
\text { área de estudo. }\end{array}$} & $\begin{array}{l}\text { Divisão em } 5 \\
\text { classes para }\end{array}$ & \multirow{9}{*}{$\begin{array}{l}\text { Setores } \\
\text { Censitários - } \\
\text { menor } \\
\text { Unidade } \\
\text { Administrativa }\end{array}$} \\
\hline & & $\begin{array}{l}\text { 2.Índice de Coleta de } \\
\text { Esgoto }\end{array}$ & $E$ & & $\begin{array}{l}\text { cada fator, de } \\
\text { acordo com a }\end{array}$ & \\
\hline & & 3.Índice de Coleta de Lixo & L & & $\begin{array}{l}\text { sendo: Muito } \\
\text { Baixa, Baixa }\end{array}$ & \\
\hline & & $\begin{array}{l}\text { 4. Padrão de Ordenamento } \\
\text { Urbano }\end{array}$ & $U$ & & $\begin{array}{l}\text { Média, Alta e } \\
\text { Muito Alta. }\end{array}$ & \\
\hline & & 4.a) Sistema Viário & V & & $\begin{array}{l}\text { Definido por } \\
\text { interpretação } \\
\text { de Imagens } \\
\text { áreas } \\
\text { ortorreitificadas } \\
\text { (IJSN } \\
\text { 2013/2014). }\end{array}$ & \\
\hline & & 4.b) Pavimentação & AV & & $\begin{array}{l}\text { Definido pelos } \\
\text { dados dos } \\
\text { Setores } \\
\text { Censitários. }\end{array}$ & \\
\hline & & 5. Índice de Renda & $E$ & & $\begin{array}{l}\text { Inversão dos } \\
\text { valores ao }\end{array}$ & \\
\hline & & 6. Índice de Instrução & $\mathrm{N}$ & & $\begin{array}{l}\text { na fórmula, } \\
\text { compreendendo } \\
\text { que terá uma } \\
\text { maior influência } \\
\text { no resultado } \\
\text { final quem } \\
\text { obtém a menor } \\
\text { renda e/ou } \\
\text { instrução e vice- } \\
\text { versa. }\end{array}$ & \\
\hline DP & Dano Potencial & 1. Densidade de População & $P$ & $\begin{array}{l}\text { Relação entre a } \\
\text { quantidade de } \\
\text { moradias e } \\
\text { moradores } \\
\text { também por } \\
\text { Setor } \\
\text { Censitário. }\end{array}$ & & \\
\hline
\end{tabular}

Fonte: Adaptado de FERREIRA \& ROSSINI-PENTEADO (2011). Distribuição dos fatores e suas classes para cada variável que compõe a fórmula de Risco. 
Tabela 1 - Valores atribuídos para o cálculo do fator de Indução de Uso e Cobertura da Terra (PI).

\begin{tabular}{|l|l|}
\hline Classes de Uso e Ocupação da Terra & Peso \\
\hline Água e Mata; & 0,1 \\
\hline Agrácola em Regeneração e Silvicultura; Pastagem; & 0,3 \\
\hline Grandes Equipamentos; & 0,5 \\
\hline Ocupação Inconsolidada ${ }^{2} ;$ & 0,7 \\
\hline $\begin{array}{l}\text { Residencial, comercial e serviços; Afloramento } \\
\text { Rochoso e campo rupestre/altitude; }\end{array}$ & 0,9 \\
\hline
\end{tabular}

Fonte: Adaptado de FERREIRA \& ROSSINI-PENTEADO (2011). Pesos atribuídos para o fator de Indução de Uso e Cobertura da Terra (PI).

Quadro 5 - Planos de informação utilizados para obtenção dos produtos cartográficos.

\begin{tabular}{|l|l|l|l|}
\hline Dados Cartográficos & Fonte/Ano & Escala & Aspectos Analisados \\
\hline $\begin{array}{l}\text { Imagens Aéreas } \\
\text { (Ortofotos) }\end{array}$ & $\begin{array}{l}\text { IEMA } \\
(2007 / 2008)\end{array}$ & $1: 15000$ & $\begin{array}{l}\text { Refinamento do mapa de Uso e } \\
\text { Cobertura da Terra }\end{array}$ \\
\hline $\begin{array}{l}\text { Imagens Aéreas } \\
\text { (Ortofotos) }\end{array}$ & $\begin{array}{l}\text { IJSN } \\
(2013 / 2014)\end{array}$ & $1: 5000$ & $\begin{array}{l}\text { Confecção de mapa de Uso e Cobertura } \\
\text { da Terra para a área de estudo e } \\
\text { produção de mapa de lineamentos. }\end{array}$ \\
\hline Estado do Espírito Santo & $\begin{array}{l}\text { GEOBASES } \\
\text { (2010) }\end{array}$ & - & $\begin{array}{l}\text { Dados utilizados para a confecção dos } \\
\text { mapas de declividade, hipsometria, } \\
\text { excedente hídrico, curvas de nível, } \\
\text { malha rodoviária, limites municipais e } \\
\text { estaduais, rede de drenagem, massa } \\
\text { d'água, etc. }\end{array}$ \\
\hline
\end{tabular}

Fonte: NASCIMENTO (2016). Dados cartográficos utilizados na produção dos mapas temáticos.

Para obtenção dos mapas finais de Risco, Perigo, Vulnerabilidade e Dano Potencial, todos os fatores foram inseridos em fórmulas ${ }^{3}$ na calculadora raster. Para Perigo, somente o fator (PI) obteve atribuição de pesos para as classes (tabela 1); para os

\footnotetext{
${ }^{2}$ O termo é uma alteração da classe "Área desocupada" proposto em Ferreira \& Rossini-Penteado (2011). A reclassificação aconteceu por não existirem porções com essas características na área de estudo e, sim, uma ocupação pouco expressiva fora da mancha urbana principal (Sede).

${ }^{3}$ Fórmulas propostas por Ferreira \& Rossini-Penteado (2011).
} 
outros fatores, nenhum deles possui acréscimo de valor por classe; segue a fórmula (1) para criação do índice de Perigo (PE) de escorregamentos.

(1) $P E=0,1(A M)+0,3(D E)+0,1(D D)+0,1(D L)+0,1(E H)+0,3(P I)$

$(A M)=$ Amplitude Altimétrica

$(\mathrm{DE})=$ Declividade

$(D D)=$ Densidade de Drenagem

$(D L)=$ Densidade de Lineamentos

$(\mathrm{EH})=$ Excedente hídrico

$(\mathrm{PI})=$ Fator de Indução de Uso e Cobertura da Terra

O índice de Vulnerabilidade foi determinado pela quantidade de casas (domicílios) presentes em cada setor, assim, os valores são ponderados para cada classe dos itens ${ }^{4}$ : $A A, C E, C L, O U, I N$ e RE. Ou seja, as áreas de uso que não representam as classes "Residencial, Comercial e Serviços" e "Ocupação Inconsolidada” não foram classificadas (NC). Essa ponderação é feita de acordo com a situação socioeconômica encontrada em cada fator por Setor Censitário, conforme apresentado na tabela 2.

Os planos de informação de cada variável foram reclassificados de acordo com o cálculo obtido para cada Setor Censitário, conforme equações (2), (3), (4), (5), (6) e (7), em que o peso atribuído para cada classe - contido entre parênteses nas fórmulas- é multiplicado pela quantidade de domicílios no setor = ( $\mathrm{n}$ casas $)$.

(2) $A A=0,165 * n$ casas (rede geral) $+0,495 * n$ casas (poço ou nascente) $+0,825 * n$ casas (outra forma)

\footnotetext{
${ }^{4}$ Proposto por Ferreira \& Rossini-Penteado (2011).
} 
(3) $C E=0,125 * n$ casas (rede geral) $+0,375 * n$ casas (fossa séptica) $+0,625 * n$ casas (fossa rudimentar) $+0,875 * n$ casas (inadequado)

(4) $C L=0,165 * n$ casas (coletado) $+0,495 * n$ casas (queimado) $+0,825 * n$ casas (inadequado)

Para o caso específico do Padrão de Ordenamento Urbano, o peso atribuído à classe do índice de pavimentação por setor foi multiplicado pela classe correspondente e o mesmo ocorreu com o fator sistema viário tendo sido obtida a média entre eles para o resultado final de OU.

(5) OU = PAVIMENTAÇÃO + SISTEMA VIÁRIO/2

Para atribuir o índice de instrução por setor, dividiu-se em quantidades percentuais de alfabetizados e atribuímos pesos para as classes, salientando que há uma inversão dos valores, visto que o maior grau de instrução representa uma influência mínima e viceversa. Esta mesma inversão ocorreu para a variável (RE); vale frisar que os valores de renda são atribuídos por notas ${ }^{5}$ apresentadas na tabela 2, não sendo representados por valores percentuais.

(6) IN $=0,1 *$ pessoas $(80-100 \%)+0,3 *$ pessoas $(60-80 \%)+0,5 *$ pessoas $(40-60 \%)+$ 0,7 pessoas $(20-40 \%)+0,9$ * pessoas $(0-20 \%)$

(7) $\mathrm{RE}=2 *$ pessoas (0-2 salários mínimos) + 5*pessoas (2-5 salários mínimos) + 10*pessoas ( $5-10$ salários mínimos) + 20* pessoas (> 20 salários mínimos)

\footnotetext{
${ }^{5}$ Conforme metodologia apresentada em Ferreira e Rossini-Penteado (2011).
} 
Por fim, com os valores obtidos em cada índice, aplicou-se na calculadora raster a equação (8), gerando o resultado para o índice de vulnerabilidade, conforme descrito na metodologia de Ferreira e Rossini-Penteado (2011).

(8) $V=((A A+C E+C L+O U) / 4)+(I N+R E) / 2)) / 2$

O índice de Dano Potencial foi obtido com as informações do censo demográfico do IBGE, de 2010, sobre a quantidade de domicílios particulares permanentes e domicílios coletivos divididos sobre a quantidade de moradores em domicílios particulares e domicílios coletivos que existiam em cada setor.

Com todas essas etapas finalizadas, chegamos à fórmula final de risco (9), obtendo um mapa qualitativo em que toda a área de estudo pode ser qualificada com alguma classe de risco entre Muito Baixo e Muito Alto.

(9) $R=P * V * D P$

Tabela 2 - Características do índice de Vulnerabilidade.

\begin{tabular}{|c|c|c|c|}
\hline Atributos/Fator & Descrição & Classes & $\begin{array}{l}\text { Índice de } \\
\text { Vulnerabilidade }\end{array}$ \\
\hline \multirow{3}{*}{$\begin{array}{l}\text { (AA) } \\
\text { Abastecimento } \\
\text { de Água }\end{array}$} & \multirow{3}{*}{$\begin{array}{l}\text { Expressa as condições de } \\
\text { abastecimento de água }\end{array}$} & Rede Geral & 0,165 \\
\hline & & $\begin{array}{l}\text { Poço ou Nascente na } \\
\text { propriedade }\end{array}$ & 0,495 \\
\hline & & Inadequado & 0,825 \\
\hline \multirow{4}{*}{$\begin{array}{l}\text { (CE) Coleta de } \\
\text { Esgoto }\end{array}$} & \multirow{4}{*}{$\begin{array}{l}\text { Expressa as condições de coleta } \\
\text { de esgoto }\end{array}$} & $\begin{array}{l}\text { Rede Geral de Esgoto ou } \\
\text { pluvial }\end{array}$ & 0,125 \\
\hline & & Fossa séptica & 0,375 \\
\hline & & Fossa rudimentar & 0,625 \\
\hline & & Inadequado & 0,875 \\
\hline$(\mathrm{CL})$ Coleta de & Expressa as condições do sistema & Serviço de limpeza & 0,165 \\
\hline
\end{tabular}




\begin{tabular}{|c|c|c|c|}
\hline \multirow[t]{2}{*}{ Lixo } & \multirow[t]{2}{*}{ de coleta e destinação do lixo } & Queimado na propriedade & 0,495 \\
\hline & & Inadequado & 0,825 \\
\hline \multirow{9}{*}{$\begin{array}{l}\text { (OU) Padrão de } \\
\text { Ordenamento } \\
\text { Urbano }\end{array}$} & \multirow{4}{*}{$\begin{array}{l}\text { Sistema viário: expressa a } \\
\text { organização da ocupação dada } \\
\text { pela articulação do sistema viário, } \\
\text { das quadras e lotes }\end{array}$} & $\begin{array}{l}\text { Planejado - Conjunto } \\
\text { Residencial }\end{array}$ & 0,125 \\
\hline & & Planejado - Loteamento & 0,375 \\
\hline & & $\begin{array}{l}\text { Espontâneo Médio - Alto } \\
\text { Padrão }\end{array}$ & 0,625 \\
\hline & & Espontâneo Baixo Padrão & 0,875 \\
\hline & \multirow{5}{*}{$\begin{array}{l}\text { Pavimentação: indica a } \\
\text { impermeabilização do terreno } \\
\text { (valor médio obtido de IBGE) }\end{array}$} & $0-20 \%$ & 0,9 \\
\hline & & $20-40 \%$ & 0,7 \\
\hline & & $40-60 \%$ & 0,5 \\
\hline & & $60-80 \%$ & 0,3 \\
\hline & & $80-100 \%$ & 0,1 \\
\hline \multirow{5}{*}{ (IN) Instrução } & \multirow{5}{*}{$\begin{array}{l}\text { Expressa o número de pessoas } \\
\text { alfabetizadas em relação ao total } \\
\text { de pessoas (alfabetizados e não } \\
\text { alfabetizados). }\end{array}$} & $80-100 \%$ & 0,1 \\
\hline & & $80-60 \%$ & 0,3 \\
\hline & & $60-40 \%$ & 0,5 \\
\hline & & $40-20 \%$ & 0,7 \\
\hline & & $20-0 \%$ & 0,9 \\
\hline \multirow{4}{*}{ (RE) Renda } & \multirow{4}{*}{$\begin{array}{l}\text { Expressa a renda média da } \\
\text { população em salários mínimos }\end{array}$} & 0 a 2 & 2 \\
\hline & & 2 a 5 & 5 \\
\hline & & 5 a 10 & 10 \\
\hline & & $>10$ & 20 \\
\hline
\end{tabular}

Distribuição dos pesos para cada classe dos fatores da variável de Vulnerabilidade, em que o representa a influência mínima e 1 a influência máxima. Baseado em FERREIRA \& ROSSINI-PENTEADO (2011). Elaborado pelo autor. 
Por fim, procedemos à última etapa de execução do mapeamento, tendo uma checagem de campo para validação do produto cartográfico final. Em campo, foram coletados os pontos descritos nos mapeamentos de Setorização de Risco Alto e muito Alto da CPRM (2012) e do Plano Municipal de Redução de Risco Geológico (PMRR), 2012/2013, a fim de verificar convergências e discrepâncias entre os mapeamentos.

\section{Resultados}

Na figura 4 é apresentada a qualificação de risco obtida pela modelagem dos atributos contidos nas variáveis da fórmula de risco $(R=P * V * D P)$.

Observa-se que a qualificação de risco extrapola o limite da Sede Urbana de Santa Teresa - ES. Isso aconteceu em pontos onde há a expansão da ocupação. Tanto a Sede quanto esta expansão foram classificadas no mapa de uso e cobertura da terra (figura 5) como "Residencial, comercial e serviços" ou "Ocupação inconsolidada", sendo a estas classes atribuídos os índices de Vulnerabilidade (V) e Dano Potencial (DP). As áreas que possuem outras classificações não participaram da atribuição dessas variáveis, pois não se enquadram conceitualmente como Risco, apenas como Perigo. 


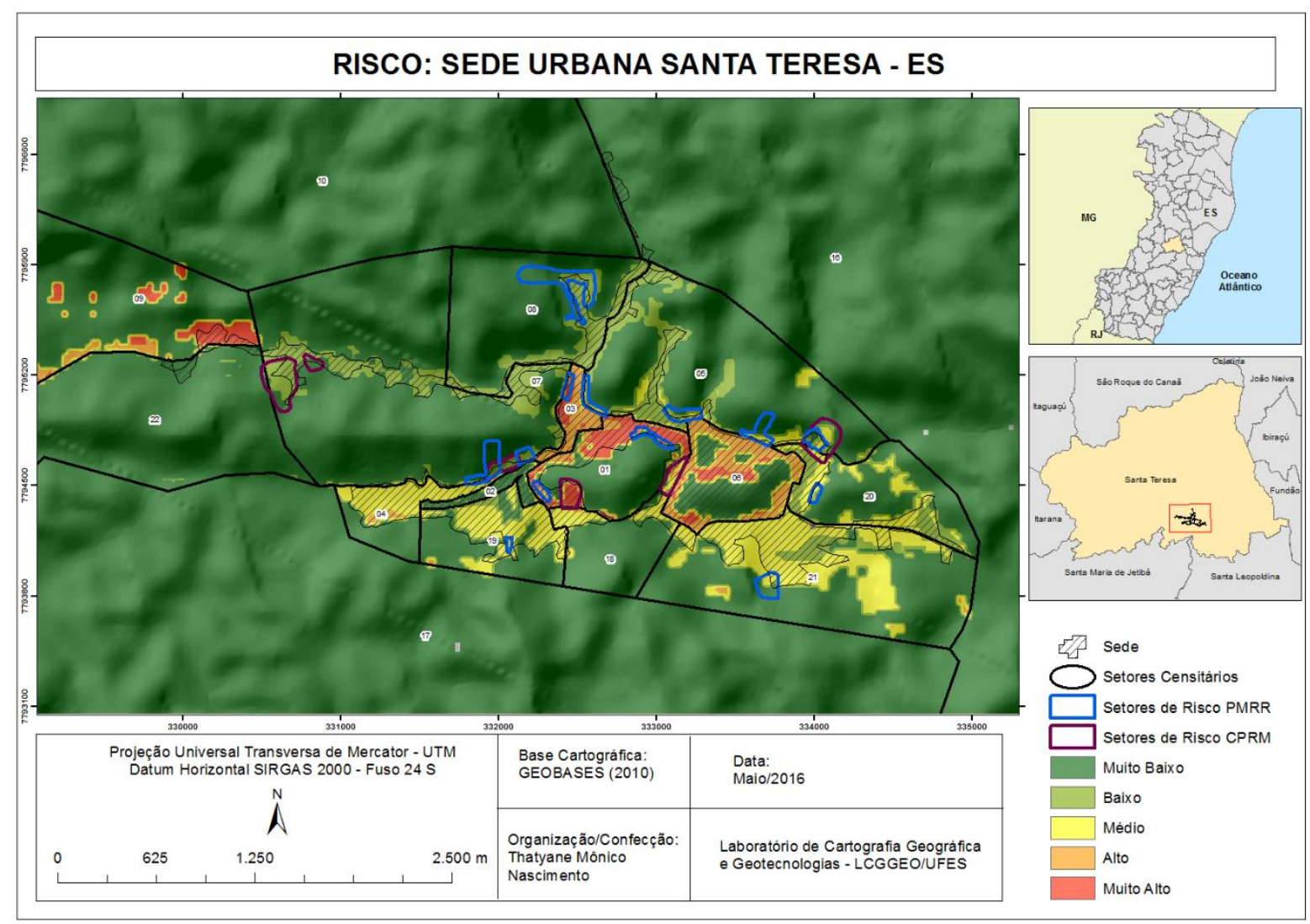

Figura 4 - Mapeamento de Risco da Área de Estudo. Elaborado pelo autor.

O mapa apresenta os setores de risco obtidos na modelagem, bem como sua distribuição por setor censitário e integra as informações de localização dos setores de risco da CPRM e do PMRR.

O risco está qualificado de acordo com as menores unidades administrativas, ou seja, os Setores Censitários. Na figura 4, eles são apresentados em polígonos na cor preta e por números (entre 01 a 10 e 16 a 22), que são os sufixos dos códigos empregados pelo IBGE, no Censo Demográfico (2010) para o Setores Censitários de Santa Teresa - ES. Optou-se em manter essa numeração para facilitar a localização desses Setores e também porque possuem classes devido a sua situação. Nesse caso, os setores de 1 a 8 e de 18 a 21 são de situação urbana e, 9, 10, 16, 17 e 22 de situação rural. É possível observar na figura 5 que a expansão da ocupação, está se ampliando nos setores rurais 9, 16 e 22. 


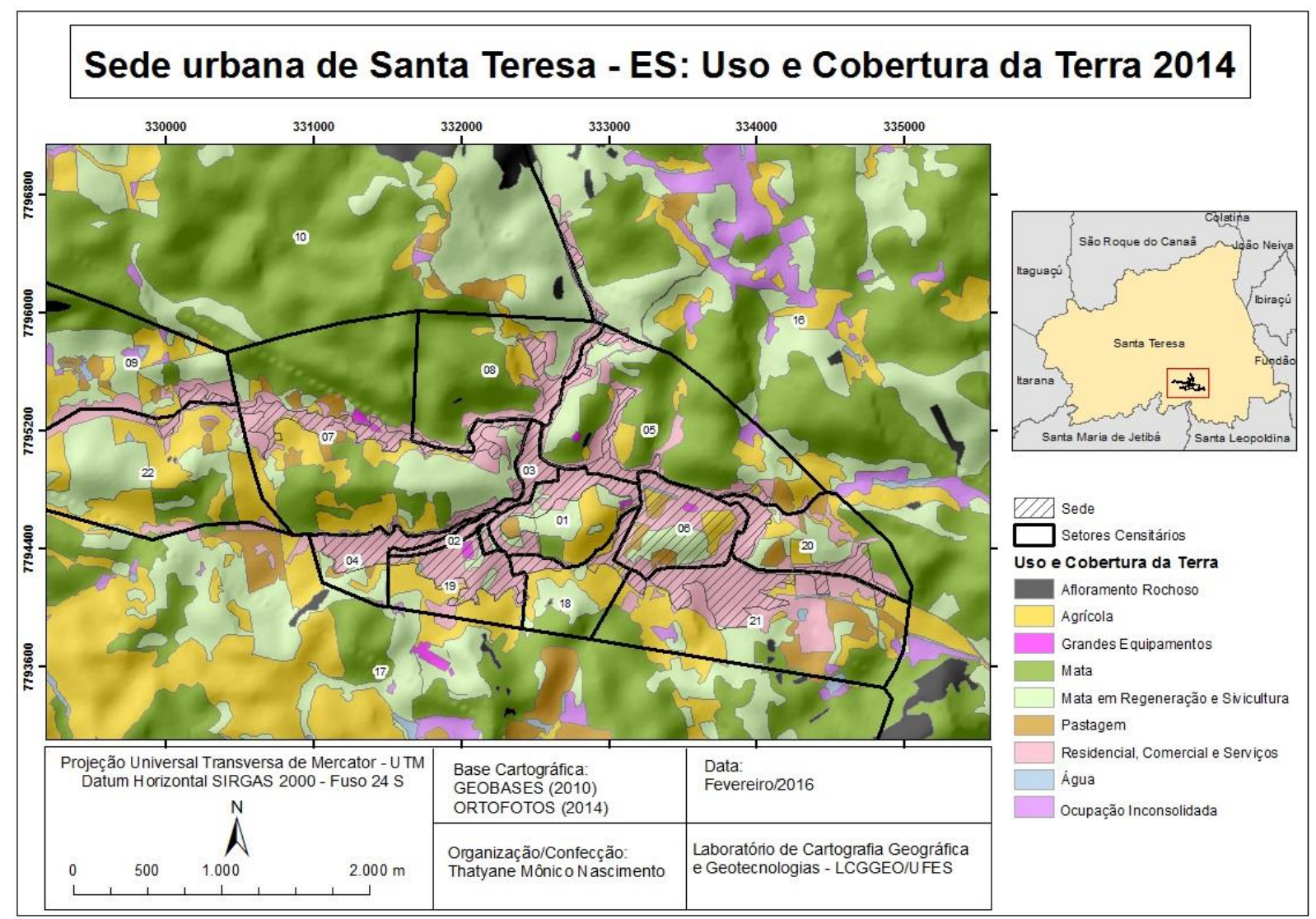

Figura 5 - Mapeamento de Uso e cobertura da terra. Elaborado pelo autor.

Mapa obtido a partir de uma reclassificação do mapa de Uso e cobertura da terra de IEMA (2008) em comparação com as ortofotos de IJSN (2014), enquadrando em classes adaptadas de FERREIRA e ROSSINIPENTEADO (2011).

Como benefício por utilizar esta metodologia híbrida, foi obtido um mapeamento que congrega as informações elencadas nas metodologias utilizadas na setorização da CPRM e do PMRR - que já estavam disponíveis - e se servir dessas informações para elencar áreas em que está havendo uma expansão da ocupação e qualificá-las, permitido pela análise integrada no SIG, fazendo assim, um refinamento desses documentos com a inserção dos dados dos Setores Censitários. Outro benefício é que os mapeamentos de CPRM e PMRR localizam setores de risco de forma pontual e, com este mapeamento, foi possível realizar um diagnóstico para toda a área da Sede Urbana de Santa Teresa - ES. São apresentadas no quadro 6 as características das variáveis analisadas no desenvolvimento de cada mapeamento. 
Fatores utilizados para cada variável que compõem o risco nos mapeamentos analisados (PMRR) e (CPRM) e do mapeamento apresentado. Elaborado pelo autor.

Quadro 6 - Comparação das variáveis empregadas nas metodologias

\begin{tabular}{|c|c|c|c|}
\hline MAPEAMENTO/FATOR & PERIGO & VULNERABILIDADE & DANO POTENCIAL \\
\hline $\begin{array}{l}\text { Setorização de risco alto e } \\
\text { muito alto (CPRM) }\end{array}$ & $\begin{array}{l}\text { Mapas sobre os } \\
\text { aspectos do meio físico }\end{array}$ & $\begin{array}{l}\text { Mapa contém } \\
\text { intervenções } \\
\text { antrópicas }\end{array}$ & $\begin{array}{l}\text { Quantidade de } \\
\text { moradias; } \\
\text { Quantidade de } \\
\text { moradores. }\end{array}$ \\
\hline PMRR & $\begin{array}{l}\text { Mapas: } \\
\text { Hipsométrico; } \\
\text { Modelo Digital do } \\
\text { Terreno (MDT); } \\
\text { Declividade; } \\
\text { Direção de encostas; } \\
\text { Curvatura Vertical; } \\
\text { Bacias Hidrográficas; } \\
\text { Geologia Geomorfologia } \\
\text { e perfis topográficos. }\end{array}$ & - & $\begin{array}{l}\text { Estimar o número } \\
\text { de moradias; } \\
\text { Padrão construtivo. }\end{array}$ \\
\hline Mapeamento proposto & $\begin{array}{l}\text { Declividade; } \\
\text { Amplitude; } \\
\text { Excedente Hídrico; } \\
\text { Densidade de } \\
\text { Lineamentos; } \\
\text { Densidade de } \\
\text { Drenagem; } \\
\text { Fator de Indução de uso } \\
\text { e cobertura da terra. }\end{array}$ & $\begin{array}{l}\text { Abastecimento de } \\
\text { água; } \\
\text { Coleta de lixo; } \\
\text { Coleta de Esgoto; } \\
\text { Padrão de } \\
\text { Ordenamento } \\
\text { Urbano; } \\
\text { Índice de Instrução; } \\
\text { Índice de Renda. }\end{array}$ & $\begin{array}{l}\text { Quantidade de } \\
\text { moradias; } \\
\text { Quantidade de } \\
\text { moradores. }\end{array}$ \\
\hline
\end{tabular}

Elaborado pelo autor. Fatores utilizados para cada variável que compõem o risco nos mapeamentos analisados (PMRR) e (CPRM) e do mapeamento apresentado.

Observa-se que pelas informações apresentadas no quadro 6 há uma tendência maior para que os produtos da CPRM e do PMRR sejam classificados mais como mapas de perigo do que propriamente de risco, pois os dados acerca dos fatores de Vulnerabilidade são ausentes ou insuficientes, e conseguem calcular o Dano Potencial, estimando a quantidade de moradias e moradores, mas a Vulnerabilidade em si não é aparentemente, o foco do produto final de risco. 
A variável de Vulnerabilidade é a que possui uma resposta mais predominante no fator de risco, neste caso, apontando novas áreas de risco, mediante as novas frentes de ocupação urbana. Sobre esta variável, trabalhos como o de Freitas e Cunha (2013) indicam que, para que se obtenha alguma precisão nos mapeamentos de risco, embora entendê-la de forma qualitativa e quantitativa dependa de fatores ora subjetivos, ela é imprescindível e vai ao encontro do que é indicado pelas Nações Unidas "para o enfrentamento com qualidade dos riscos de desastres, no sentido de minimizar as perdas e os danos à sociedade, à economia e ao ambiente" (FREITAS; CUNHA, 2013, p. 19). Na figura 6 é possível ver a qualificação obtida para cada índice.

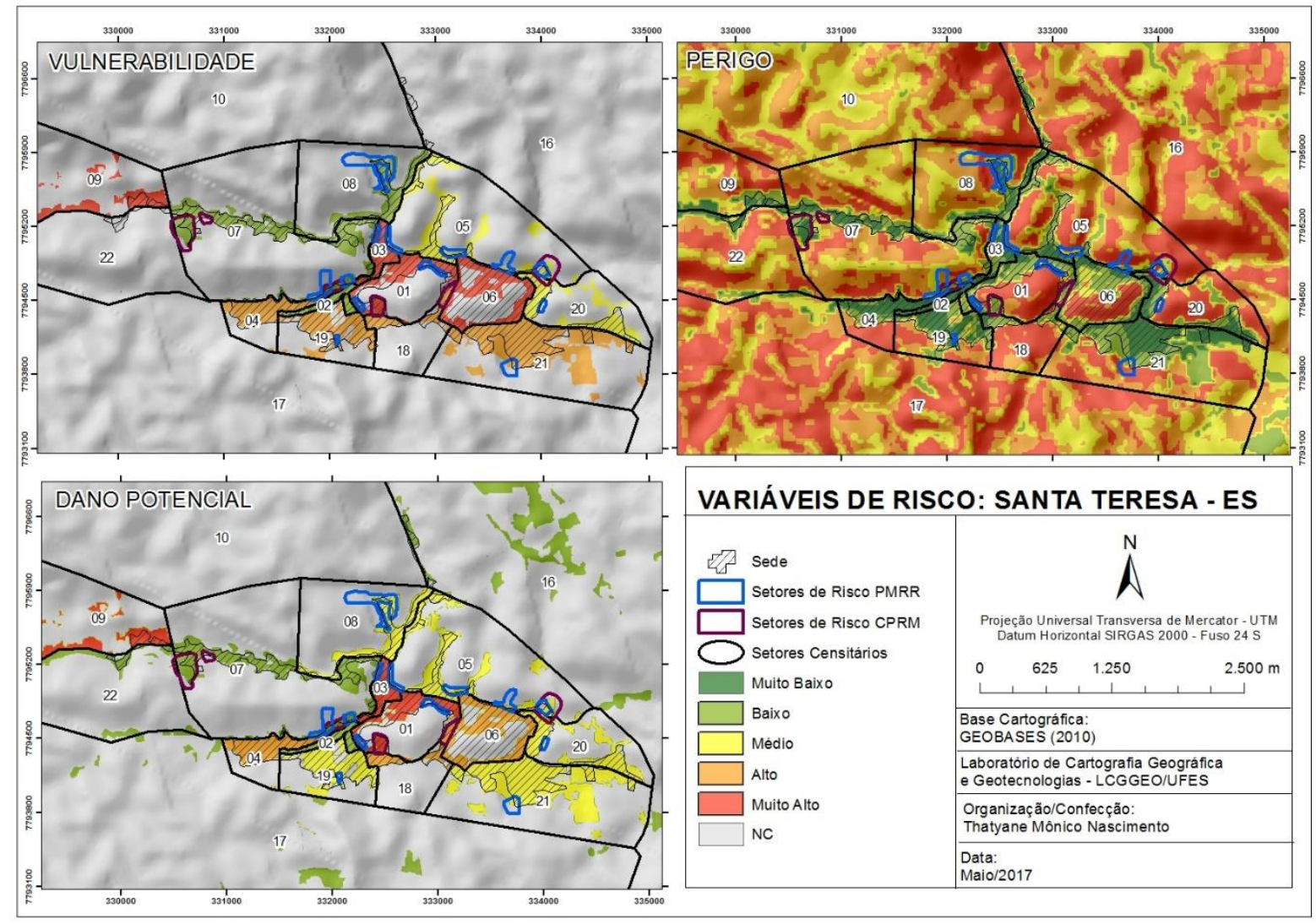

Figura 6 - Índices de Perigo, Vulnerabilidade e Dano Potencial. Elaborado pelo autor.

Mapa das variáveis que compõem o Risco. NC = a Não Classificado, corresponde às áreas em que a Vulnerabilidade e o Dano Potencial não podem ser mensurados conforme classificação do Uso e cobertura da terra. 
A análise e discussão foram enviesadas de acordo com a localização dos Setores Censitários e da distribuição dos setores de risco de CPRM e do PMRR e sua qualificação apresentados na figura 7. As informações adicionais sobre os setores de risco e as comparações entres índices dos mapeamentos estão nos quadros 7 e 8 . A ficha de campo utilizada para checagem de convergências e divergências é um checklist dos pontos frisados por CPRM e PMRR em seus relatórios técnicos (fatores condicionantes do risco geológico como geologia, relevo, vegetação e "formações antrópicas"; agentes potencializadores e índices de movimentação).

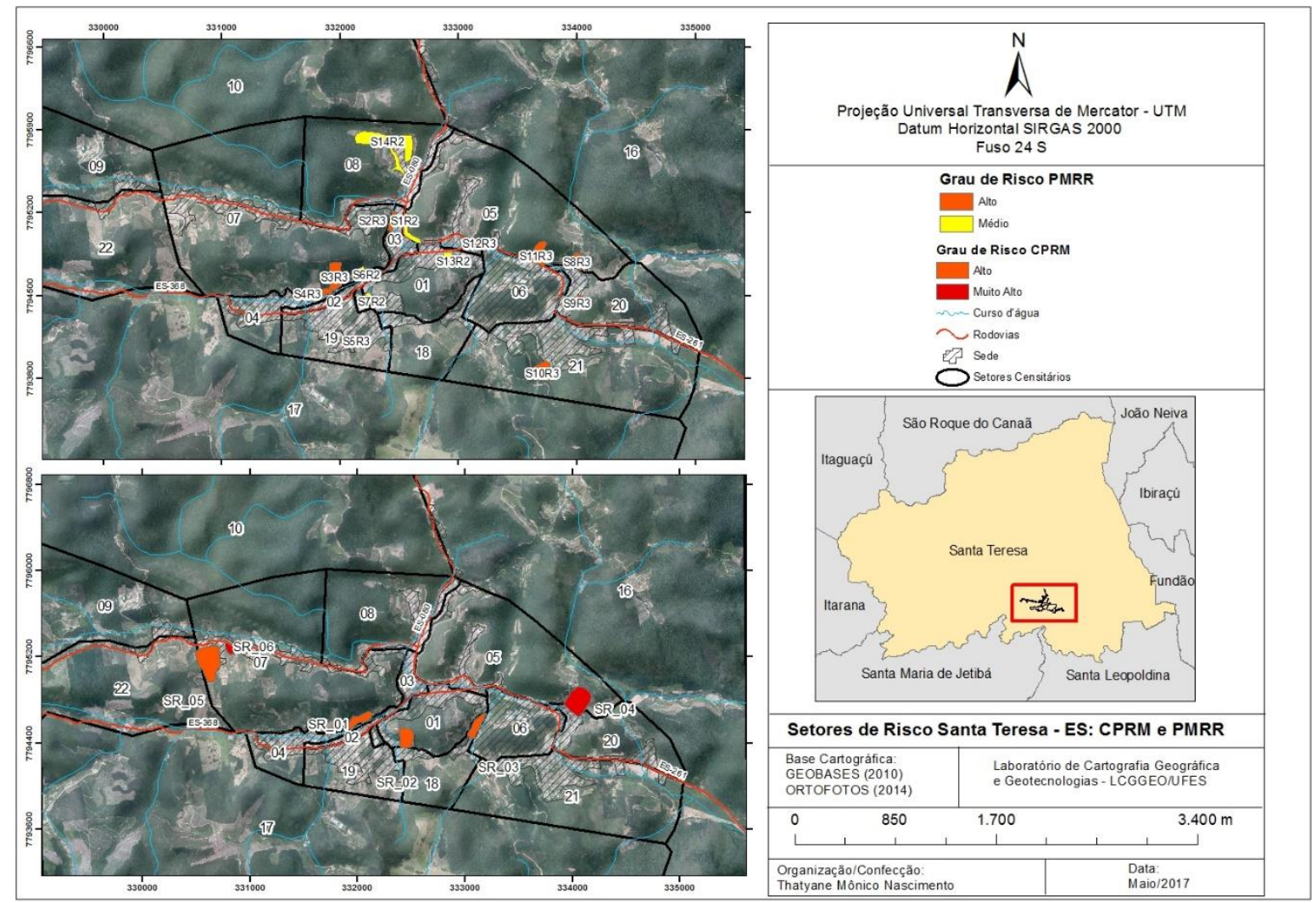

Figura 7 - Mapa dos Setores de risco da CPRM e do PMRR. Elaborado pelo autor. Apresentação dos setores de risco de PMRR com o código SXRX e de CPRM com o código SR_XX. 
Quadro 7 - Setores de Risco da CPRM.

\begin{tabular}{|c|c|c|c|c|c|c|}
\hline Setor de Risco & $\begin{array}{l}\text { Grau de } \\
\text { risco }\end{array}$ & Tipologia & $\begin{array}{l}\text { Setor } \\
\text { Censitário }\end{array}$ & Bairro & & Índices \\
\hline \multirow{4}{*}{ SR_01 } & \multirow{4}{*}{ Alto } & \multirow{4}{*}{ Escorregamento planar } & \multirow{4}{*}{07} & \multirow{4}{*}{ Vila Nova } & $\mathrm{R}$ & Baixo \\
\hline & & & & & $P$ & Baixo \\
\hline & & & & & V & Baixo \\
\hline & & & & & DP & Baixo \\
\hline \multirow{4}{*}{ SR_02 } & \multirow{4}{*}{ Alto } & \multirow{4}{*}{ Escorregamento planar } & \multirow{4}{*}{01} & \multirow{4}{*}{ Alvorada } & $\mathrm{R}$ & Muito Alto \\
\hline & & & & & $P$ & $\begin{array}{l}\text { Baixo para } \\
\text { Médio }\end{array}$ \\
\hline & & & & & V & Muito Alto \\
\hline & & & & & DP & Muito Alto \\
\hline \multirow{4}{*}{ SR_03 } & \multirow{4}{*}{ Alto } & \multirow{4}{*}{ Escorregamento planar } & \multirow{4}{*}{18} & \multirow{4}{*}{$\begin{array}{l}\text { Dois } \\
\text { Pinheiros }\end{array}$} & $\mathrm{R}$ & Médio/Alto \\
\hline & & & & & $P$ & $\begin{array}{l}\text { Baixo para } \\
\text { Médio }\end{array}$ \\
\hline & & & & & $\mathrm{V}$ & Alto \\
\hline & & & & & DP & Alto \\
\hline \multirow{4}{*}{ SR_04 } & \multirow{4}{*}{ Muito Alto } & \multirow{4}{*}{ Escorregamento planar } & \multirow{4}{*}{05} & \multirow{4}{*}{ Centenário } & $\mathrm{R}$ & Médio \\
\hline & & & & & $P$ & $\begin{array}{l}\text { Médio para } \\
\text { Muito Alto }\end{array}$ \\
\hline & & & & & V & Médio \\
\hline & & & & & DP & Médio \\
\hline \multirow{4}{*}{ SR_05 } & \multirow{4}{*}{ Alto } & \multirow{4}{*}{ Escorregamento planar } & \multirow{4}{*}{07} & \multirow{4}{*}{$\begin{array}{l}\text { São } \\
\text { Lourenço }\end{array}$} & $\mathrm{R}$ & Baixo \\
\hline & & & & & $P$ & $\begin{array}{l}\text { Muito Baixo e } \\
\text { Baixo }\end{array}$ \\
\hline & & & & & $\mathrm{V}$ & Baixo \\
\hline & & & & & DP & Baixo \\
\hline \multirow{4}{*}{ SR_06 } & \multirow{4}{*}{ Muito Alto } & \multirow{4}{*}{ Escorregamento planar } & \multirow{4}{*}{07} & \multirow{4}{*}{$\begin{array}{l}\text { São } \\
\text { Lourenço }\end{array}$} & $\mathrm{R}$ & Baixo \\
\hline & & & & & $P$ & Alto \\
\hline & & & & & $\mathrm{V}$ & Baixo \\
\hline & & & & & DP & Baixo \\
\hline
\end{tabular}

Elaborado pelo autor. Apresentação dos códigos dos setores de risco da CPRM, sua qualificação e distribuição por Setor Censitário e a correspondência com o grau de risco no mapeamento desenvolvido neste estudo 
Quadro 8 - Setores de Risco de PMRR.

\begin{tabular}{|c|c|c|c|c|c|c|}
\hline $\begin{array}{l}\text { Setor de } \\
\text { risco }\end{array}$ & $\begin{array}{l}\text { Grau de } \\
\text { risco }\end{array}$ & Tipologia & $\begin{array}{l}\text { Setor } \\
\text { Censitário }\end{array}$ & Bairro & \multicolumn{2}{|c|}{ Índices } \\
\hline \multirow{4}{*}{ S1R2 } & \multirow{4}{*}{ Médio } & \multirow{4}{*}{$\begin{array}{l}\text { Deslizamento de } \\
\text { solo }\end{array}$} & \multirow{4}{*}{05} & \multirow{4}{*}{ Centro } & $\mathrm{R}$ & Médio \\
\hline & & & & & $P$ & Baixo para Médio \\
\hline & & & & & $\mathrm{V}$ & Médio \\
\hline & & & & & DP & Médio \\
\hline \multirow{4}{*}{$\mathrm{S}_{2} \mathrm{R}_{3}$} & \multirow{4}{*}{ Alto } & \multirow{4}{*}{$\begin{array}{l}\text { Deslizamento de } \\
\text { solo }\end{array}$} & \multirow{4}{*}{03} & \multirow{4}{*}{ Centro } & $\mathrm{R}$ & Muito alto/ Alto \\
\hline & & & & & $P$ & Baixo \\
\hline & & & & & $\mathrm{V}$ & Alto \\
\hline & & & & & DP & Alto \\
\hline \multirow{4}{*}{$S_{3} R_{3}$} & \multirow{4}{*}{ Alto } & \multirow{4}{*}{$\begin{array}{l}\text { Deslizamento de } \\
\text { solo }\end{array}$} & \multirow{4}{*}{07} & \multirow{4}{*}{ Vila Nova } & $\mathrm{R}$ & Baixo \\
\hline & & & & & $P$ & Entre Alto a Baixo \\
\hline & & & & & $\mathrm{V}$ & Baixo \\
\hline & & & & & DP & Baixo \\
\hline \multirow{4}{*}{$\mathrm{S}_{4} \mathrm{R}_{3}$} & \multirow{4}{*}{ Alto } & \multirow{4}{*}{$\begin{array}{l}\text { Deslizamento de } \\
\text { solo }\end{array}$} & \multirow{4}{*}{07} & \multirow{4}{*}{ Vila Nova } & $\mathrm{R}$ & Médio a Baixo \\
\hline & & & & & $P$ & Baixo \\
\hline & & & & & $\mathrm{V}$ & Baixo \\
\hline & & & & & DP & Baixo \\
\hline \multirow{4}{*}{$\mathrm{S}_{5} \mathrm{R}_{3}$} & \multirow{4}{*}{ Alto } & \multirow{4}{*}{$\begin{array}{l}\text { Deslizamento de } \\
\text { solo }\end{array}$} & \multirow{4}{*}{19} & \multirow{4}{*}{ Vila Nova } & $\mathrm{R}$ & Médio \\
\hline & & & & & $P$ & Muito Baixo/ Baixo \\
\hline & & & & & $\mathrm{V}$ & Alto \\
\hline & & & & & DP & Médio \\
\hline \multirow{4}{*}{ S6R2 } & \multirow{4}{*}{ Médio } & & & & $\mathrm{R}$ & Baixo \\
\hline & & Deslizamento de & 07 & Vila Nova & $P$ & Baixo \\
\hline & & & 年 & 要 & $\mathrm{V}$ & Baixo \\
\hline & & & & & DP & Baixo \\
\hline & & & & & $\mathrm{R}$ & $\begin{array}{l}\text { Alto/ porções de } \\
\text { Muito Alto }\end{array}$ \\
\hline S7R2 & Médio & $\begin{array}{l}\text { Deslizamento de } \\
\text { solo e Rolamento }\end{array}$ & 01 & Alvorada & $P$ & Baixo para Médio \\
\hline & & de bloco & & & $\mathrm{V}$ & Alto \\
\hline & & & & & $\mathrm{DP}$ & Alto \\
\hline & & & & & $\mathrm{R}$ & Médio \\
\hline$S 8 R z$ & Alto & Deslizamento de & 05 & João & $P$ & Médio \\
\hline S & (1ivo & de bloco & S & Miglioreli & $\mathrm{V}$ & Médio \\
\hline & & & & & DP & Médio \\
\hline $\mathrm{SgR}_{3}$ & Alto & Deslizamento de & 20 & João & $\mathrm{R}$ & Médio \\
\hline & & solo & & Miglioreli & $P$ & Médio \\
\hline
\end{tabular}




\begin{tabular}{|c|c|c|c|c|c|c|}
\hline & & & & & V & Médio \\
\hline & & & & & DP & Médio \\
\hline \multirow{4}{*}{$\mathrm{S}_{10 R 3}$} & \multirow{4}{*}{ Alto } & \multirow{4}{*}{$\begin{array}{l}\text { Deslizamento de } \\
\text { solo }\end{array}$} & \multirow{4}{*}{21} & \multirow{4}{*}{$\begin{array}{l}\text { Jardim } \quad \mathrm{da} \\
\text { Montanha }\end{array}$} & $\mathrm{R}$ & Médio \\
\hline & & & & & $P$ & $\begin{array}{l}\text { Muito Alto para } \\
\text { Baixo }\end{array}$ \\
\hline & & & & & V & Alto \\
\hline & & & & & $\mathrm{DP}$ & Médio \\
\hline \multirow{4}{*}{$\mathrm{S}_{11 \mathrm{R}} 3$} & \multirow{4}{*}{ Alto } & \multirow{4}{*}{$\begin{array}{l}\text { Deslizamento de } \\
\text { solo }\end{array}$} & \multirow{4}{*}{05} & \multirow{4}{*}{ Dois Pinheiros } & $R$ & Médio \\
\hline & & & & & $P$ & $\begin{array}{l}\text { Muito Alto para } \\
\text { Baixo }\end{array}$ \\
\hline & & & & & $\mathrm{V}$ & Médio \\
\hline & & & & & DP & Médio \\
\hline \multirow{4}{*}{$\mathrm{S}_{12 \mathrm{R}} 3$} & \multirow{4}{*}{ Alto } & \multirow{4}{*}{$\begin{array}{l}\text { Deslizamento de } \\
\text { solo }\end{array}$} & \multirow{4}{*}{05} & \multirow{4}{*}{$\begin{array}{l}\text { Dois Pinheiros e } \\
\text { Centro }\end{array}$} & $\mathrm{R}$ & $\begin{array}{l}\text { Porções de Alto a } \\
\text { Baixo }\end{array}$ \\
\hline & & & & & $P$ & Muito alto a médio \\
\hline & & & & & V & Médio \\
\hline & & & & & DP & Médio \\
\hline \multirow{4}{*}{ S13R2 } & \multirow{4}{*}{ Médio } & \multirow{4}{*}{$\begin{array}{l}\text { Deslizamento de } \\
\text { solo }\end{array}$} & \multirow{4}{*}{01} & \multirow{4}{*}{$\begin{array}{l}\text { Centro e Vila } \\
\text { Nova }\end{array}$} & $R$ & Alto/Muito Alto \\
\hline & & & & & $P$ & Muito Alto a Médio \\
\hline & & & & & V & Muito Alto \\
\hline & & & & & $\mathrm{DP}$ & Muito Alto \\
\hline \multirow{4}{*}{ S14R2 } & \multirow{4}{*}{ Médio } & \multirow{4}{*}{$\begin{array}{l}\text { Deslizamento de } \\
\text { solo }\end{array}$} & \multirow{4}{*}{08} & \multirow{4}{*}{$\begin{array}{l}\text { Recanto do Vale / } \\
\text { Canaã }\end{array}$} & $R$ & Baixo \\
\hline & & & & & $P$ & Baixo \\
\hline & & & & & V & Baixo \\
\hline & & & & & DP & Médio \\
\hline
\end{tabular}

Elaborado pelo autor. O código de setor também vem acompanhado do seu grau de Risco, exposto pela letra $\mathrm{R}$.

O mapeamento de CPRM e o mapa aqui proposto obteve um grau de $50 \%$ de aproximação convergente e de 50\% divergente. Sobre a convergência, os setores SR_03 e SR_04 apresentam classificações múltiplas dentro deles, alcançando a mesma classificação empregada por CPRM. Foi verificado que há alterações dos graus de risco de alto para muito alto no SR_02 porque houve um adensamento urbano pronunciado neste setor e adjacências (figura 8).

Quanto às discrepâncias, elas são observadas em SR_01, SR_05 e SR_06, todos eles inseridos dentro do domínio do setor censitário 7. Acredita-se que neste setor 
censitário as informações sobre V e DP por serem "Baixo" denotaram a qualificação de risco final, juntamente com a informação de Perigo dos setores SR_01 e SR_05 que também foi “Baixo”, ambos localizados em um fundo de vale. Já o SR_06, observa-se que obteve em Perigo uma classificação “Alto”, principalmente pelo fator de inclinação dessa variável para este setor; contudo, na modelagem final, os valores não foram suficientes para que obtivesse uma classificação de risco maior.

O setor censitário 7 é uma zona quase que linear de expansão da Sede do município, quando observamos a direção da ocupação também evoluindo no próximo setor censitário 9 de situação rural (Loteamento São Lourenço - figura 9). Outro setor censitário que está passando por essa expansão de forma mais desordenada é o setor 21, que na classificação de risco final deste mapeamento obteve qualificação média para quase todo o setor.

Acredita-se que isso aconteceu porque as informações de V e DP são relativas ao Censo demográfico de 2010 e não representam em totalidade a realidade; em conversa informal com moradores da localidade de setor censitário 9, os mesmos afirmaram ter havido um aumento da construção de moradias e substituição de mata nativa por cultivos agrícolas no bairro São Lourenço, alterando as condições das vertentes do entorno, sendo possível por meio deste mapeamento elencar áreas proativas a alguma qualificação de risco mais alta que ainda não tivesse sido setorizada.

Ao analisar a classificação obtida para esses setores de risco localizados no setor censitário 7, surgiram hipóteses sobre a varlável de Perigo quanto ao seu método, podendo incluir nessa variável um mapa de cicatrizes das vertentes ao redor destes fundos de vale setorizados com algum tipo de risco, a fim de contabilizar essa área com alguma qualificação mais significativa por se tornarem, assim, áreas de depósito de materiais em um possível episódio de escorregamento, sendo imprescindível para esses estudos de prevenção manter dados cadastrais atualizados sobre áreas com ocorrência de fenômenos de escorregamento.

Outro ponto sobre o produto final desta modelagem para a qualificação do Risco é que a classificação é uma divisão entre os valores obtidos para a área, neste estudo, e 
utilizou a classificação "natural break jenks" no programa ArcGis 10.3, conforme metodologia que baseia o trabalho. O estudo apontou que como a reclassificação do raster é para toda a área de estudo, a divisão segue os valores obtidos para a área, o que não exclui o fato de outras áreas de estudo apresentarem valores diferentes, logo classificações diferentes. Assim, se faz necessário a criação de parâmetros para esses valores, finalidade esta que o trabalho não alcançou.

Sobre a questão dos valores empregados na classificação, temos o caso dos setores do PMRR S5R3, S8R3, S9R3, S10R3 e S11R3 (referentes aos setores censitários 19, $5,20,21,5$ e 5 respectivamente), que neste trabalho foram enquadrados com qualificação "Médio" de Risco em relação a qualificação "Alto" de PMRR. Acredita-se que isso aconteceu devido às condições encontradas em outras porções da área de estudo que evidenciavam situações mais claras em que o risco poderia ser "Alto" ou "Muito Alto". No caso de S5R3, a modelagem apresenta valores de V e DP mais altos e S10R3 e S11R3 de Perigo mais alto, mas não foram suficientes para alterar essa condição "Médio". Na checagem de campo, esses setores apresentam evidências de Risco, mas em uma situação mais estabilizada do que em outras porções.

Observamos que boa parte dessa qualificação "Médio" encontra-se no setor censitário 5, que possui muitos setores de risco, mas que não possui uma ocupação tão expressiva comparada a outros setores censitários. Sobre as convergências temos os setores de risco S1R2, S2R3 e S12R3, que se confirmaram em campo com a qualificação de risco empregada, referentes aos setores censitários 5, 3 e 5, respectivamente. Novamente, no caso dos setores de risco localizados no setor censitário 5, temos uma qualificação “Médio" e em S12R3, uma qualificação que permeia de "Alto, Médio e Baixo".

Sobre a evolução do grau de Risco para classificações mais altas, temos S7R2 e S13R2 que passou de "Médio" em PMRR para "Alto a Muito Alto" neste mapeamento (figura 8). Ambos os setores estão localizados em setor censitário 1 com qualificações "Alto a Muito Alto" em todas as variáveis que compõem o Risco; encontram-se no Bairro Centro e as alterações antrópicas denotam essa condição, também encontrada no mapeamento de CPRM, tendo classificação "Alto". 
As maiores divergências foram encontradas nos setores de risco S3R3 (setor censitário 7) e SR43 (setor censitário 4) de “Alto" em PMRR, para "Baixo" e "Médio a Baixo" respectivamente no mapeamento aqui proposto e, de S6R2 e S14R2 de "Médio" em PMRR para "Baixo” neste mapeamento. Sobre S3R3 a divergência é apontada pelos dados do setor censitário 7, discorrido anteriormente. S6R2, encontra-se em fundo de Vale, e sua classificação em Perigo deveria ser mais alta, porque as vertentes do entorno denotam essa condição mais perigosa, podendo alterar essa condição de Risco, futuramente.

Em relação a S14R2, temos DP como "Médio", porém as outras variáveis não são tão expressivas, o que na classificação final vai de encontro com uma classificação mais baixa. Este setor censitário também sofreu uma evolução da ocupação não demonstrada pelos dados inseridos no SIG, mas perceptíveis em campo. Sobre S4R3, é que temos a maior divergência, pois este setor encontra-se no bairro Vila Nova e sofre com muitas intervenções na parte média e superior de suas vertentes, tendo ocorrido diversos episódios de movimentação do terreno. 


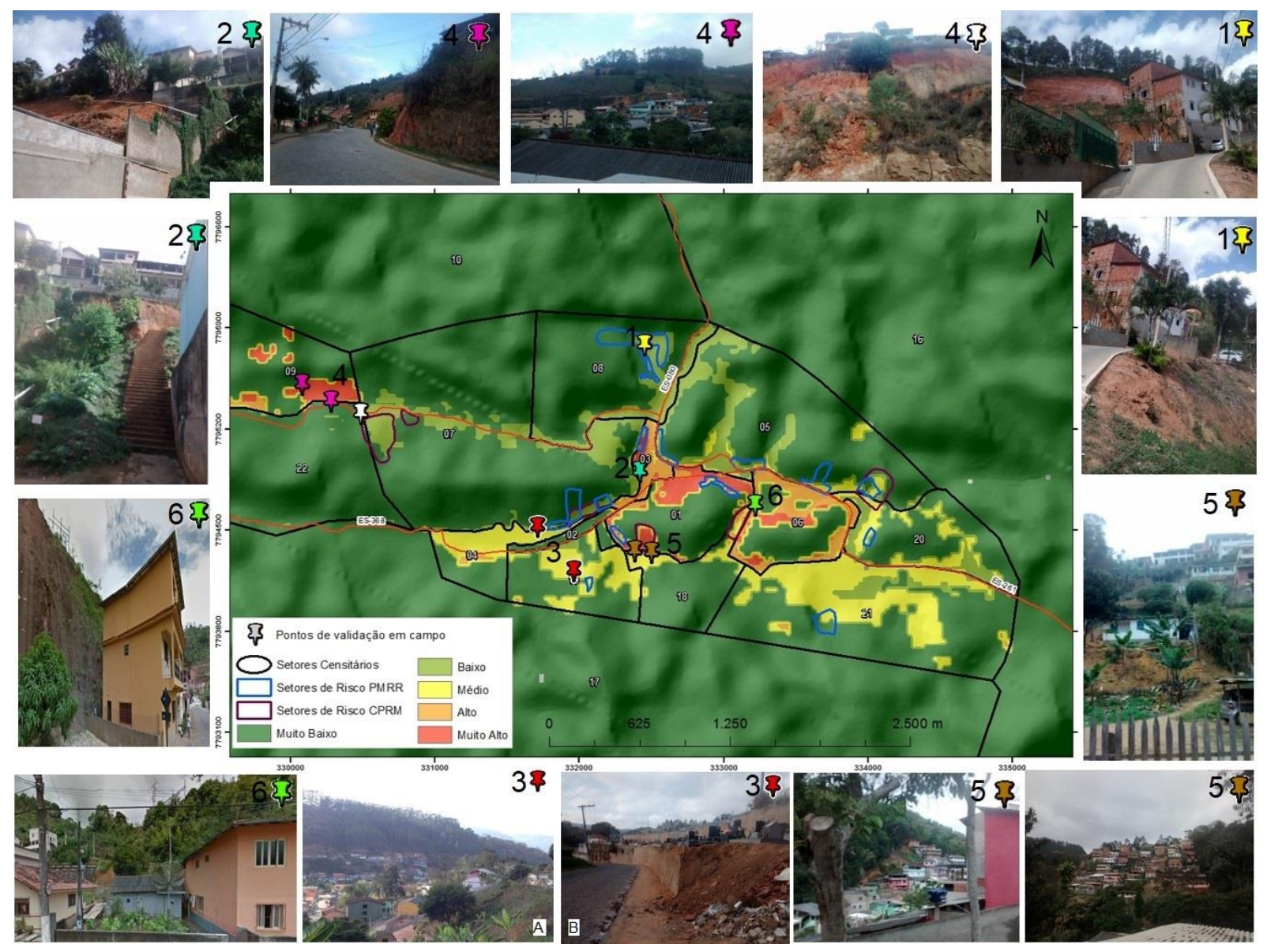

Figura 8 - Mapa síntese Sede Urbana de Santa Teresa - ES. Elaborado pelo autor.

(1) contém S14R2 evolução da ocupação para a porção média da vertente e presença de topo ocupado por pastagem e cultivos agrícolas registro divergente da situação encontrada em campo por PMRR. (2) contém $\mathrm{S} 2 \mathrm{R} 3_{3}$ no bairro Centro, setor censitário 3, com classificação de alto a muito alto. Corte situado entre duas escolas municipais, lançamento de esgoto e lixo na vertente. (3) Bairro Vila Nova compreendendo os setores de risco $\mathrm{S}_{4} \mathrm{R}_{3}$, situação crítica da evolução da ocupação, (3a) adensamento na parte média e topo de morro ocupado por cultivos e (3b) deslocamento do material dessa vertente onde está localizado um

cemitério. Situação divergente dos setores S4_R3, S3_3 e SR_01, mais convergentes com a situação apresentada no bairro Vila nova, porém localizados em setor censitário 7. (4) Setor censitário 7, marcador branco, situação de evolução da ocupação com evento de movimentação (SR_05). Marcador rosa, evolução da ocupação no bairro São Lourenço, setor censitário 9 de situação rural, topo ocupado ao longo da vertente. (5) Aumento do grau de risco para os setores localizados no setor censitário 1 ocupação extremamente adensada, pouco servida de infraestrutura urbana, aumentando o grau de risco, contém S7R2 e SR_02. (6) contém SR_03 convergências com situação encontrada por CPRM. 

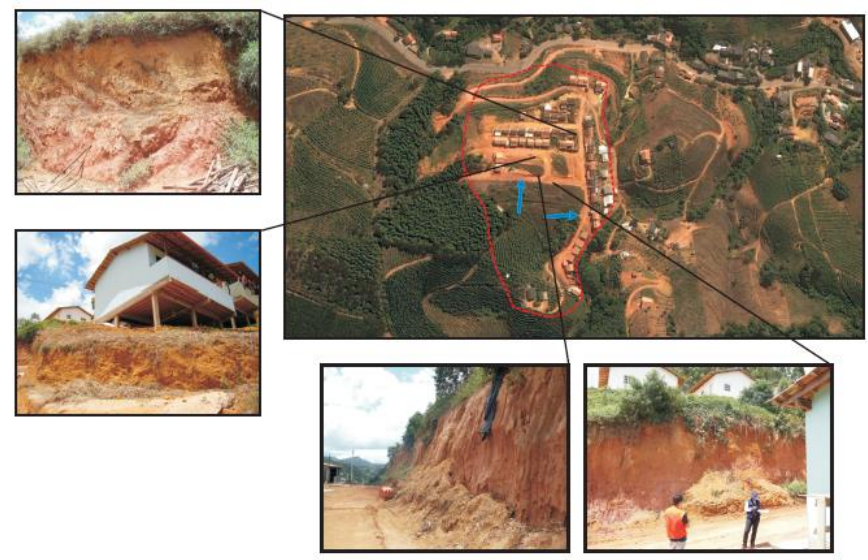

Figura 9 - Loteamento São Lourenço. Fonte: CPRM (2012).

Setor 05 elencado pela CPRM, Loteamento São Lourenço em fase de abertura de cortes para estabelecimento de ocupação urbana em 2012. Este adensamento é ainda maior, confirmado pela etapa de campo em 2016 e evidenciado na figura 8 pelo marcador branco.

\section{Conclusão}

Para esse tipo de estudo, o mapeamento apontou que é necessário ter dados atualizados sobre a condição socioeconômica da área analisada (Vulnerabilidade), condição essa que é extremamente dinâmica, para maior acurácia do resultado final. Nos Setores Censitários que estão passando por expansão da ocupação foi possível justificar a discrepância com os outros mapeamentos, devido à falta de informações atualizadas, visto que o Censo é do ano de 2010.

Quanto às informações sobre o Perigo, para esta área de estudo específica, se faz importante um bom refinamento do Uso e Cobertura da Terra, visto que a área tem uma característica polivalente, pois é uma Sede Urbana que dispõe de cultivos agrícolas e atividades de silvicultura em meio à ocupação totalmente urbana; este fator deve receber atenção especial na modelagem do produto final, pois estas intervenções antrópicas alteram a qualificação de risco, mesmo que não seja de característica urbana.

O trabalho também concluiu que a validação de campo é fundamental, sobretudo, porque este mapeamento teve apenas duas etapas de campo, uma para reconhecimento da área e outra para a checagem final, pois mesmo com produtos de alta resolução, como o uso das ortofotos para refinamento, por exemplo do mapeamento de uso e cobertura da terra, ainda há nuances que não puderam ser observadas para que a checagem de 
campo cumpra seu papel de inferir o grau de risco final. Também apontou que é possível fazer um mapeamento com metodologia híbrida que é proativo em indicar pontos de atenção para Gestão, utilizando-se dos SIGs em boa parte de sua execução e de outras informações que já estavam disponíveis, o que acarreta um custo muito menor na execução deste tipo de trabalho e em relação ao tempo empregado.

No desenvolvimento de dissertação acadêmica que deu origem a este artigo, na metodologia estava prevista a inclusão de um mapa dos principais eventos e acidentes de processos de escorregamento, contudo, a falta de registros em órgãos públicos de forma sistematizada inviabilizou esta etapa. Atualmente, o S2ID integra essas informações, porém com dados de eventos ocorridos de 2013 até o presente e, mesmo assim, ainda não é utilizado como uma plataforma para registro de forma contínua devido a burocracias do próprio sistema, poucos técnicos para fazer checagem e registro das áreas avaliadas nos municípios, etc., utilizando este canal online, em grande maioria, para obtenção apenas de recursos financeiros quando decretada uma situação de calamidade pública, por exemplo. Isso se faz imprescindível em termos de Gestão e, a ausência desses registros inviabilizou uma análise mais profunda sobre os fenômenos geológicos já ocorridos $^{6}$ no município de Santa Teresa-ES.

Em termos de gestão e diretrizes previstas na lei 12.608/2012, no que tange os mapeamentos, entende-se que os conceitos empregados sobre o Risco precisam ser melhor refletidos, como nesse caso que ao observar as metodologias dos mapeamentos que mais servem as Defesas Civis, os mesmos contam com uma análise muito mais do Perigo, do que o risco propriamente dito, o que não os descaracteriza. Contudo, entendese que o tema é ainda muito recente e que boa parte desses conceitos estão em fase de construção e também passam por traduções indiscriminadas, o que atrapalha corpo técnico, pesquisadores e sociedade civil a chegarem a uma definição exata.

\footnotetext{
${ }^{6}$ Neste caso, era possível verificar apenas um registro de eventos associados a escorregamentos, referente aos episódios de fortes chuvas entre o final de 2013 e início de 2014 relacionado a este tipo de decreto. (Nascimento, 2016).
} 


\section{Referências}

ALMEIDA, Lutiane Queiroz de. Por uma ciência dos riscos e vulnerabilidades na geografia. Mercator - Revista de Geografia da UFC. v.10, n 23, 2011, p. 83-99. Disponível em: <http://www.mercator.ufc.br/index.php/mercator/article/viewArticle/559> Acesso em: 05 dez. 2016.

BRASIL. Ministério da Ciência, Tecnologia, Inovações e Comunicações. CEMADEN inaugura novas instalações e celebra posse do diretor. Brasília: ASCOM, 2015. Disponível em: <http://www.mcti.gov.br/noticia/-/asset_publisher/epbVopr6elSo/content/cemadeninaugura-novas-instalacoes-e-celebra-posse-do-diretor>. Acesso em: 27 mai. 2017.

BRASIL. Ministério da Integração Nacional. Instrução Normativa $\mathbf{n}^{\circ}$ 01, de 24 de janeiro de 2012. Estabelece procedimentos e critérios para a decretação de situação de emergência ou estado de calamidade pública pelos Municípios, Estados e pelo Distrito Federal, e para o reconhecimento federal das situações de anormalidade decretadas pelos entes federativos e dá outras providências. Brasília, 2012. Disponível em: http://www.mi.gov.br/c/document_library/get_file?uuid=822a4d42-970b-4e80-93f8daee395a52d1\&groupld=30109. Acesso em 22/06/2016.

BRASIL. Ministério da Integração. Histórico da Defesa Civil. Brasília, 2016. Disponível em: <http://www.mi.gov.br/historico-sedec>. Acesso em: 27 mai. 2017.

BRASIL. Ministério da Ciência, Tecnologia e Informação. Centro Nacional de Monitoramento e Alertas de Desastres Naturais (CEMADEN). Brasília, 2017. Disponível em: <http://www.mcti.gov.br/cemaden>. Acesso em: 27 mai. 2017.

COMPANHIA DE PROSPECÇÃO E RECURSOS MINERAIS. Setorização de risco alto e muito alto: Santa Teresa (ES). Brasília: CPRM, 2012.

COMPANHIA DE PROSPECÇÃO E RECURSOS MINERAIS. Serviço Geológico do Brasil. Setorização de riscos geológicos: Espírito Santo: CRM, 2016. Disponível em: <http://cprm.gov.br/publique/Gestao-Territorial/Geologia-de-Engenharia-e-RiscosGeologicos/Setorizacao-de-Riscos-Geologicos-4138.html\#espiritosanto>. Acesso em: 27 mai. 2017.

DALMAU, Marcos Baptista Lopez; MACHAD, Mari Angela; FRAN, Ana Carolina Vicenzi. A Campanha Cidades Resilientes e o Plano Nacional de Gestão de Riscos e Desastres Naturais: avanços e perspectivas na construção de comunidades menos vulneráveis. Cadernos Adenauer: Cidades Resilientes, Rio de Janeiro: Fundação Konrad Adenauer, n.2, p.95-113, ago. 2015. Disponível em: <http://www.kas.de/wf/doc/16608-1442-5-30.pdf>. Acesso em: 27 abr. 2015. 
DINIZ, Noris Costa et al. Cartografia geotécnica. São Paulo: Ipt, 2012. 37 p. Disponível em: <https://gestaorisco.files.wordpress.com/2012/11/capitulo-3-cartografia-geotecnica.pdf>. Acesso em: 14 jul. 2015.

FERREIRA, Cláudio José. Gestão de riscos e desastres (relacionados a perigos) naturais. In: Zoneamento ecológico-econômico: base para o desenvolvimento sustentável do Estado de São Paulo. Seminário 12 a 14 de dezembro de 2011 [recurso eletrônico]. São Paulo: SMA, 2011. Cap. 3, p. 159-167. Disponível em: <http://www.ambiente.sp.gov.br/cpla/files/2013/03/Seminario_ZEE_web.pdf >. Acesso em: 05 dez. 2016

FERREIRA, Claudio José; ROSSINI-PENTEADO, Denise. Mapeamento de risco a escorregamento e inundação por meio da abordagem quantitativa da paisagem em escala regional. In:

CONGRESSO BRASILEIRO DE GEOLOGIA DE ENGENHARIA, 11, São Paulo, 2011. Anais... São Paulo: ABGE, 2011. Disponível em: <http://www.dpi.inpe.br/spring/portugues/arquivos_publicacoes/Ferreira\&RossiniPenteado_com_tutorial.pdf $>$. Acesso em: 05 dez. 2016.

FREITAS, Maria Isabel Castreghini; CUNHA, Lúcio. Cartografia da vulnerabilidade socioambiental: convergências e divergências a partir de algumas experiências em Portugal e no Brasil. Revista Brasileira de Gestão Urbana, v. 5, n. 1, p.15-31, jun. 2013. Disponível em: <http://www.scielo.br/pdf/urbe/v5n1/a03v5n1.pdf>. Acesso em: 29 maio 2017.

INSTITUTO BRASILEIRO DE GEOGRAFIA E ESTATÍSTICA. Malhas digitais censo demográfico 2010: Setores Censitários ES. Rio de Janeiro: IBGE, 2010. Disponível em: <ftp://geoftp.ibge.gov.br/malhas_digitais/censo_2010/setores_censitarios/es/>. Acesso em: 18 jun. 2016.

MACEDO, Eduardo Soares; OGURA, Agostinho Tadashi; SANTORO, Jair. O que é um plano de contingência ou preventivo de defesa civil. In: CARVALHO, Celso Santos e GALVÃO, Thiago. (Orgs.). Prevenção de riscos de deslizamentos em encostas: guia para elaboração de políticas municipais. Brasília: Ministério das Cidades: Cities Alliance, 2006, p. 78-91.

NASCIMENTO, Thatyane Mônico. Avaliação de Metodologias de Mapeamento Aplicado à Redução de Risco à Escorregamentos na Sede Urbana de Santa Teresa - ES. 2016. 161 f. Dissertação (Mestrado) - Curso de Geografia, Universidade Federal do Espírito Santo, Vitória, 2016.2 Disponível em: <http://portais4.ufes.br/posgrad/teses/tese_10223_dissertacao_thatyane_nascimento.pdf >. Acesso em: 23 jun. 2017.

ZEMLYA (Org.). Plano Municipal de Redução de Risco Geológico: Santa Teresa - ES. Vitória: 2013. 
SÃO PAULO. Instituto Geológico. Secretaria de Meio Ambiente. Prestação de serviços. 2004. Disponível em: <http://www.igeologico.sp.gov.br/ps_ppdc.asp>. Acesso em: 27 maio 2017.

SÃO PAULO. Instituto Geológico. Coordenadoria de Planejamento Ambiental. Secretaria do Meio Ambiente do Estado de São Paulo. Unidades homogêneas de uso e ocupação do solo urbano (UHCT) do Estado de São Paulo. São Paulo, 2014. Disponível em: <http://s.ambiente.sp.gov.br/cpla/Ficha_Tecnica_UHCT.pdf>. Acesso em: 05 dez. 2016.

SILVA, C. 2004. Serviço Geológico do Brasil - SGB/CPRM. In: TOMINAGA, L. K.; PEJON, O. J \& BASTOS, C. A. (Coord.) 2004. Diagnóstico preliminar da cartografia geotécnica e geoambiental no Brasil. In: PEJON, O.; ZUQUETTE, L. eds. Simpósio Brasileiro de Cartografia Geotécnica e Geoambiental, 5: 2004: São Carlo. p. 01 - 20. Disponível em: <http://www.redetec.org.br/wp-

content/uploads/2015/02/DiagnosticoCartografiaGeotecnica.pdf>. Acesso em: 29 set. 2016.

TOMINAGA, Lídia Keiko. Avaliação de metodologias de Análise de Risco a Escorregamentos: aplicação de um ensaio em Ubatuba, SP. 2007. 220 f. Tese (Doutorado) - Universidade de São Paulo, Curso de Geografia, Departamento de Geografia da Faculdade de Letras e Ciências Humanas. São Paulo, 2007. Cap. 220. Disponível em: <http://www.teses.usp.br/teses/disponiveis/8/8135/tde-18102007-155204/pt-br.php>. Acesso em: 05 dez. 2016.

TOMINAGA, Lídia Keiko. Análise e mapeamento de risco. In: TOMINAGA, Lídia Keiko; SANTORO, Jair; AMARAL, Rosangela do. Desastres naturais: conhecer para prevenir. São Paulo: Instituo Geológico, 2009. Cap. 9, p. 147-160.

UNISDR. International Decade for Natural Disaster Reduction: General Assembly. 1989.

Recebido em: 08/12/2016 Aprovado em: 05/06/2017

Universidade do Estado de Santa Catarina - UDESC Centro de Ciências Humanas e da Educação - FAED

Revista PerCursos

Volume 18 - Número 36 - Ano 2017 revistapercursos@gmail.com 